THERMAL-HYDRAULIC ANALYSIS OF RVACS TRANSIENT IN PRISM USING COMMIX-1AR: QUASI-STEADY STATE RESULTS AFTER ONE DAY

by

P. L. Garner

Applied Physics Division

Argonne National Laboratory

9700 South Cass Avenue

Argonne, Illinois 60439

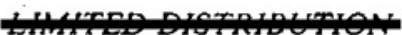

TIe-AMLPRISM-TM series provides the documentation of results for thamive tasks perforn prepared prin preliminary a This document is not considered OUO-Applied Technology. It was reviewed for Export Controlled Information and found to be suitable for

4 series is ported are quoted or

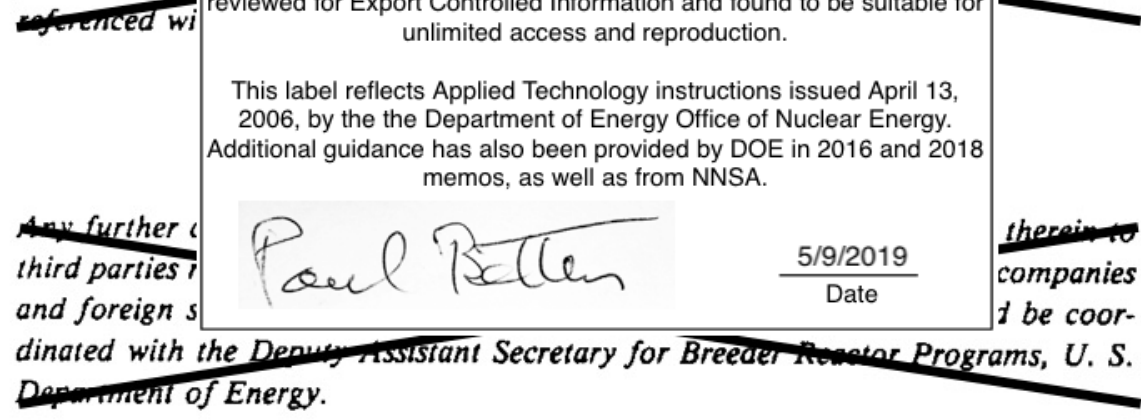


I. INTRODUCTION . . . . . . . . . . . . . . . . . . . . 1

II. MODEL DESCRIPTION AND BOUNDARY CONDITIONS . . . . . . . . . . . 2

III. RESULTS . . . . . . . . . . . . . . . . . . . 4

A. Without Overflow ................. 4

B. With Overflow ................ . . 7

IV. CONCLUSIONS . . . . . . . . . . . . . . . . . . 9

V. REFERENCES ....................... . . . 10

APPENDIX A - Figures Showing Temperatures in Alternate Units . . . . . A-1 


\section{LIST OF FIGURES}

1. Elevation View of COMMIX Model at Azimuthal Planes

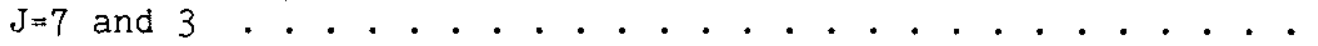

2. Plan View of Commix Model Just Below Pump Outlet Plenum

(Axial Plane $\mathrm{K}=11$ ) . . . . . . . . . . . . . . 12

3. Elevation View of Velocity Distribution Calculated by

COMMIX for QSS at 1 Day Without Overfiow . . . . . . . . 13

4. Velocity Distribution Calculated by COMMIX in RVL/RV Gap

for QSS at 1 Day Without Overflow . . . . . . . . . . 14

5. Velocity Distribution Calculated by COMMIX in RV/GV Gap

for "QSS at 1 Day Without Overflow . . . . . . . . . . . 15

6. Elevation View of Temperature Distribution $\left[{ }^{\circ} \mathrm{C}\right]$ Calculated

by COMMIX for QSS at 1 Day Without Overflow . . . . . . 16

7. Temperature Distribution $\left[{ }^{\circ} \mathrm{C}\right]$ Calculated by COMMIX in

RVL/RV Gap for QSS at 1 Day Without Overflow . . . . . . . . 17

8. Temperature Distribution $\left[{ }^{\circ} \mathrm{C}\right]$ Calculated by COMMIX in RV/GV Gap for QSS at 1 Day Without Overflow ........ 18

9. Temperature Distribution $\left[{ }^{\circ} \mathrm{C}\right]$ Calculated by COMMIX in GV/CC Gap for QSS at 1 Day Without Overflow . . . . . . . . . 19

10. Representative Radial Temperature Distribution $\left[{ }^{\circ} \mathrm{C}\right]$

Calculated by COMMIX at Top of Hot Pool for QSS at 1 Day

Without Overflow . . . . . . . . . . . . . . 20

11. Elevation View of Velocity Distribution Calculated by

COMMIX for QSS at 1 Day With Overflow . . . . . . . . . 21

12. Velocity Distribution Calculated by COMMIX in RV/GV Gap

for QSS at 1 Day With Overflow . . . . . . . . . . 22

13. Elevation View of Temperature Distribution $\left[{ }^{\circ} \mathrm{C}\right]$ Calculated

by COMMIX for QSS at 1 Day With Overflow . . . . . . . . 23

14. Temperature Distribution $\left[{ }^{\circ} \mathrm{C}\right]$ Calculated by COMMIX in

RVL/RV Gap for QSS at I Day With Overflow . . . . . . . . . 24

15. Temperature Distribution $\left[{ }^{\circ} \mathrm{C}\right]$ Calculated by COMMIX in

RV/GV Gap for QSS at 1 Day With Overflow . . . . . . . . . 25

16. Temperature Distribution $\left[{ }^{\circ} \mathrm{C}\right]$ Calculated by COMMIX in

GV/CC Gap for QSS at 1 Day With Overflow . . . . . . . . 26 
17. Representative Radial Temperature Distribution $\left[{ }^{\circ} \mathrm{C}\right]$ Calculated by COMMIX at Top of Hot Pool for QSS at 1 Day With Overflow . . . . . . . . . . . . . . . 27

A-6. Elevation View of Temperature Distribution $\left[{ }^{\circ} \mathrm{F}\right]$ Calculated by COMMIX for QSS at 1 Day Without Overflow . . . . . . . . A-2

A-7. Temperature Distribution $\left[{ }^{\circ} \mathrm{F}\right]$ Calculated by COMMIX in RVL/RV Gap for QSS at 1 Day Without Overflow . . . . . . . A-3

A-8. Temperature Distribution $\left[{ }^{\circ} \mathrm{F}\right]$ Calculated by COMMIX in $\mathrm{RV} / \mathrm{GV}$ Gap for QSS at 1 Day Without Overflow . . . . . . . A-4

$\mathrm{A}-9$. Temperature Distribution $\left[{ }^{\circ} \mathrm{F}\right]$ Calculated by COMMIX in GV/CC Gap for QSS at 1 Day Without Overflow . . . . . . . A-5

$A-10$. Representative Radial Temperature Distribution [ $\left.{ }^{\circ} \mathrm{F}\right]$ Calculated by COMMIX at Top of Hot Pool for QSS at 1 Day Without overflow ............... . A-6

A-13. Elevation View of Temperature Distribution $\left[{ }^{\circ} \mathrm{F}\right]$ Calculated by COMMIX for QSS at 1 Day With Overflow . . . . A-7

A-14. Temperature Distribution $\left[{ }^{\circ} \mathrm{F}\right]$ Calculated by COMMIX in RVL/RV Gap for QSS at 1 Day With Overflow . . . . . . . A-8

A-15. Temperature Distribution [ $\left.{ }^{\circ} \mathrm{F}\right]$ Calculated by COMMIX in RV/GV Gap for QSS at 1 Day With Overflow . . . . . . . A-9

A-16. Temperature Distribution [ $\left.{ }^{\circ} \mathrm{F}\right]$ Calculated by COMMIX in GV/CC Gap for QSS at 1 Day With Overflow . . . . . . . $\mathrm{A}-10$

A-17. Representative Radial Temperature Distribution [ $\left.{ }^{\circ} \mathrm{F}\right]$ Calculated by COMMIX at Top of Hot Pool for QSS at 1 Day with overflow ................. . . A-11 
vi 


\title{
THERMAL-HYDRAULIC ANALYSIS OF RVACS TRANSIENT IN PRISM USING COMMIX-1AR: QUASI-STEADY STATE RESULTS AFTER ONE DAY
}

P. L. Garner

\section{ABSTRACT}

\begin{abstract}
The PRISM reactor has been analyzed at conditions corresponding to 1 day following initiation of an RVACS transient, in which all pumping power is lost and the post-scram decay power ( $0.58 \%$ of nominal) is being removed from the reactor vessel solely by natural circulation of air through the reactor vessel auxiliary cooling system. The IFR-variant of the COMMIX$1 \mathrm{AR}$ computer code was used to calculate the three-dimensional fluid flow and temperature fields within the primary system and its immediate surroundings. Relative to full-power/full-flow conditions, the sodium is found to circulate through the primary system in a natural convection mode at a flow rate of $1.5-1.9 \%$ and the temperatures are found to be $150-270^{\circ} \mathrm{C}\left(270-490^{\circ} \mathrm{F}\right)$ hotter. If sodium from the hot pool is allowed to return to the cold pool via an overflow path, then this results in a decreased flow through the normal return path via the intermediate heat exchanger. Inclusion of the overflow path had little apparent long term effect on the efficiency of heat removal via the reactor vessel auxiliary cooling system or on primary sodium temperatures. Appreciable differences could exist for transients during which the intermediate heat exchanger interacts with active intermediate and secondary systems; this needs to be investigated further.
\end{abstract}




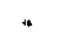

*

viii 


\section{INTRODUCTION}

An important safety feature of the Power Reactor Inherently Safe Module (PRISM) design (Ref. 1) is provision for a path through which atmospheric air flows by natural convection over the outside surface of the primary system at all times. The flow path in this reactor vessel auxiliary cooling system (RVACS) is sized to insure system integrity by removing post-scram decay heat generation in a totally passive manner in the event that all active heat removal components are rendered unavaliable during a transient. Under these conditions, the sodium flow within the primary system would undergo a transition from forced to natural circulation mode, the latter being driven by thermal gradients in the system. A proper analysis of these of $f$-normal transients requires a coupled solution of the fluid flow and heat transfer equations in three spatial dimensions and in time. This analysis capability is provided by the COMMIX computer code, a version of which is used in the present analysis.

The present work examines one portion of an "RVACS transient", which was initiated by a loss of power to all primary and intermediate system coolant pumps and accompanied by a reactor scram. A steady-state calculation has been performed using as boundary conditions those expected at one specific time in the transient; this calculational approach is denoted quasi-steady state (QSS). The specific time selected is 1 day after initiation; preliminary lumped-parameter analyses ${ }^{1}$ indicate that this is the approximate time at which the power removed by the RVACS will exceed the power generated in the core. This corresponds to the beginning of the longterm (1-2 months) cooldown phase of the transient and system temperatures should be at their maximum values. The QSS approach should provide a reasonably good estimate of the fluid flow and temperature fields, since the lumped-parameter analyses predict that changes are occurring slowly at this point in the transient. This approach is not a substitute for performing the full transient calculation in three dimensions but is an expedient way of scoping the long-term coolability of the system and provides a reference against which the transient calculation may be compared when performed.

The remainder of this report presents the way in which the COMMIX code was used to calculate the conditions expected 1 day after initiation of the 
RVACS transient. The effect of preventing versus allowing sodium from the hot pool to return to the cold pool via an overflow path is considered. This work is a continuation of the full-power/full-flow steady-state analysis presented in Ref. 2 and forms the second part of a comprehensive thermal-hydraulics analysis program for PRISM. This report supersedes the analysis presented in Ref. 3 and incorporates revisions to the reactor design, the structure of the CommIX model, and the transient conditions.

\section{MODEL DESCRIPTION AND BOUNDARY CONDITIONS}

The present calculations were performed using the IFR-variant of the COMMIX-1AR computer code (Ref. 4). In addition to the normal porous medium formulation of the mass, momentum, and energy conservation equations in three dimensions found in all COMMIX code versions, the IFR-variant allows for multiple fluids to be considered in physically separated regions of the calculational domain and allows for radiative heat transfer between surfaces of thermal structures. The specific version of the code contained a preliminary formulation of the radiative heat transfer model, which was less rigorous than in the version used for the steady-state calculations reported in Ref. 2; although this should not be a significant factor in the results, the difference is noted for completeness.

The calculation used the same $90^{\circ}$ sector representation of the primary system and surroundings as was used for the steady-state calculations reported in Ref. 2. The major features of the geometry are illustrated in Figs. 1 and 2. The normal sodium flow pattern is up through the pump duct (cells (I-radial, J-azimuthal, $\mathrm{K}$-axial) $=(6,3,8-11)$ ) to the pump outlet plenum (cells $(5-7,1-5,12-13)$ ); down through two pipes (azimuthal cells $\mathrm{J}=1$ ! and $J=5$ ) to the core inlet plenum (cells $(1-4,1-8,2-3)$ ); up through the assemblies (cells $(1-4,1-8,4-7)$ ) and the upper internals structure (UIS) region (celis $(1-4,1-8,8-19)$ ) to the upper portion of the hot pool (cells $(1-7,1-8,17-19))$; down through the intermediate heat exchanger (IHX) (cells $(5-7,6-8,9-16))$ to the cold pool; and up through the fixed shield region (cells $(5-6,1-8,4-6)$ ) to the pump inlet plenum (cells $(5-7,1-5,7)$ ). The annular gap between the reactor vessel (RV) and the guard vessel (GV) (cells 
$(10-11,1-8,1-19))$ contains Argon gas. The annular space between the GV and the collector cylinder (CC) cells $(12-13,1-8,1-19)$ ) is the air riser portion of the RVACS. The specifics of the geometry, along with the heat transfer and frictional resistance model parameters, are detailed in Ref. 2 and will not be repeated here.

The time into the RVACS transient was taken as approximately 1 day. This point is far enough into the transient that there is no head being supplied by the primary pumps; the mode of sodium flow within the RV is natural convection as induced by thermal gradients. There is also no flow of sodium in the intermediate loop and thus no heat rejection from the primary sodium through the IHX. The power generation is all due to fission product decay in the fuel; this generation rate ${ }^{1}$ is $2.5 \mathrm{MW}^{*}\left(8.5 \times 10^{6} \mathrm{Btu} / \mathrm{hr}\right)$, which corresponds to $0.58 \%$ of full power conditions. This heat source was located in the core fuel (cells $(1-2,1-8,5)$ ); although additional fuel was physically present in the storage rack in the model (cells $(4,1-8,8-13)$ ), its power generation was assumed to be negligible compared with that in the core. The only means of removing heat from the RV is provided by the RVACS. Even though the air mass flow through the RVACS is in a natural convection mode, the flow rate at the bottom of the riser must be specified as input to the COMMIX code, since only a portion of the RVACS is modeled. This flow rate is a function of the average RV temperature, which, in turn, is a function of the average RV surface heat flux. Since all heat generated in the fuel must pass through the RV under the QSS assumption, the RV surface heat flux is known; using the tabulation in Ref. 5, the air mass flow rate is, thus, found to be $26.6 \mathrm{~kg} / \mathrm{s}(59 \mathrm{lbm} / \mathrm{s})$. All other boundary conditions are the same as used for the full-power/full-flow calculation reported in Ref. 2 .

The PRISM design provides an alternate path for sodium in the hot pool to return to the cold pool under some transient conditions. The actuation of this alternate path is passive: if the sodium expands sufficiently during heatup, the hot pool level rises to slots cut through the upper

*All "extensive" numbers in this report are stated for the entire reactor module, not just the $90^{\circ}$ sector modeled. 
portion of the reactor vessel liner (RVL), allowing this sodium to enter the top of the annular space between the RVL and the RV, and flow downward through this gap to the cold pool. The sodium exchanges energy with RV while flowing through this gap, supplementing (or replacing) the energy removal capability normally provided by the IHXs. The COMMIX code is not able to model a free surface level and, thus, can not be used to predict the onset of overflow; therefore, separate calculations were performed which excluded and included this overflow. In both cases, the RVL/RV gap was assumed to be completely filled with sodium in the model. (The actual design conditions are such that the hot pool level is $0.46 \mathrm{~m}(1.5 \mathrm{ft})$ below the slots and the sodium level in the RVL/RV gap is $3.8 \mathrm{~m}(12.5 \mathrm{ft})$ below the slots during normal operation; the difference between these two free surface levels is a function of the pressure drops around the system.) The difference between the two cases was whether or not sodium was allowed to flow from the hot pool into the top of the RVL/RV gap. This was allowed by setting the surface permeability of the RVL (located between radial nodes $I=7$ and $I=8$ ) to a value of 0.2 at axial node $K=19$; this permeability was zero when overflow was excluded.

\section{RESULTS}

\section{A. Without Overflow}

The overall nature of the primary sodium flow field is shown in Fig. 3 . The general character of this flow is the same as found for steady state (Fig. 5 of Ref. 2). The sodium velocity magnitudes are, however, smaller in the present QSS calculation than they were at normal steady state. The primary system flow is $34 \mathrm{~kg} / \mathrm{s}\left(0.27 \times 10^{6} \mathrm{lbm} / \mathrm{hr}\right)$ and is totally due to the thermal gradients in the system. This flow is $1.5 \%$ of the steady-state value; since the power is at $0.58 \%$, the power-to-flow ratio is 0.39 . Upward flow is maintained in all core assemblies. The flow pattern in the UIS region differs from that calculated at full-power/full-flow conditions. The present calculation shows a thermally induced circulation pattern in the annular space (radial node $I=4$ ) between the UIS baffle plates and the fuel 
storage rack: flow is upward on the hot IHX side (azimuthal nodes $\mathrm{J}=6-8$ ) and downward on the cold pump side $(J=1-5)$. In contrast, all flow in this annular region was upward under the forced circulation conditions reported in Ref. 2. Similarly, circulatory flow exists in the annular gap between the fixed shielding and the RV.

The velocity distribution in the RVL/RV gap is shown in Fig. 4; the Ieft half of this figure is for $I=8$ (adjacent to the RVL), the right half is for $I=9$ (adjacent to the RV), the center corresponds to $J=1$ (pump side), and the left and right edges both correspond to $\mathrm{J}=8$ (IHX side). This flow is generally similar to that calculated at steady state (Fig. 9 of Ref. 2). The lower portion shows a circulation pattern which is upward along the middle of the IHX and downward on the pump side; there is also downward flow at $J=8$ along the IHX which was not noted at steady state. The upper portion (axial nodes $K=17-19$ ) of this field shows upflow along the RVL and downflow along the cooler RV surface.

The velocity field calculated for the Argon gas located in the RV/GV gap is shown in Fig. 5. The majority of this field shows a circulation similar to that seen in the lower portion of the RVL/RV gap. The details of this convection pattern are relatively insignificant, since $98 \%$ of the energy transfer from the $\mathrm{RV}$ to the $\mathrm{GV}$ is by thermal radiation rather than convection.

The overall character of the temperature field is shown in Fig. 6*. The sodium undergoes little temperature change between the pump and the core inlet plenum, entering the assemblies at $587^{\circ} \mathrm{C}\left(1089^{\circ} \mathrm{F}\right)$. The temperature peaks at $644^{\circ} \mathrm{C}\left(1191^{\circ} \mathrm{F}\right)$ at the top of the fuel in the driver assemblies (cells $(1,1-8,5)$ ). The temperature rise across the core is lower than found for normal steady state due, primarily, to the lower power-to-flow ratio. The temperatures in the assemblies are also affected by conduction of heat radially through the assembly walls and the fixed shields; this effect was not as noticeable at steady state where axial convection dominates the energy transport at full flow. As was the case at steady state, the

\footnotetext{
*A duplicate set of figures showing temperatures in $\left[{ }^{\circ} \mathrm{F}\right]$ is included as Appendix A.
} 
temperature becomes fairly uniform in the UIS and maintains that uniformity in the upper part of the hot pool. Sodium enters the top of the IHX at $626^{\circ} \mathrm{C}\left(1159^{\circ} \mathrm{F}\right)$. The temperature decreases by $6^{\circ} \mathrm{C}\left(11^{\circ} \mathrm{F}\right)$ while flowing downward through the IHX; the energy given up is transferred through the tube walls, stagnant intermediate sodium, IHX casing, interstitial sodium, and the RVL to the sodium in the RVL/RV gap. In contrast to the steady state result, the cold pool is not uniform in this QSS calculation; the temperature variation is primarily in the axial direction. The fluid in the cold pool is transferring energy radially to the fixed shield and to the RV, decreasing in temperature by $41^{\circ} \mathrm{C}\left(74^{\circ} \mathrm{F}\right)$ during its travel from the bottom of the IHX to the bottom of the fixed shields. About $9^{\circ} \mathrm{C}\left(16^{\circ} \mathrm{F}\right)$ of this decrease is recovered during flow upward through the fixed shields to the pump inlet. The lowest sodium temperature is in the relatively isolated region of the cold pool at $\mathrm{K}=1$, which is below the core inlet plenum; the temperature in this region is $576^{\circ} \mathrm{C}\left(1069^{\circ} \mathrm{F}\right)$. The global sodium temperatures in the QSS calculation are determined by the air temperature and energy removal mechanisms in the RVACS, which is having to remove ail of the power generated in the core. On a global basis, the primary sodium is $150-270^{\circ} \mathrm{C}\left(270-490^{\circ} \mathrm{F}\right)$ hotter than steady state in this QSS calculation, as may be seen by comparing this figure with Fig. 10 of Ref. 2 .

The temperature of the sodium in the RVL/RV gap is shown in Fig. 7 . The temperature variation is primarily in the axial direction but with a small azimuthal component; the temperature variation in the radial direction is negligible. This temperature distribution is consistent with the velocity distribution shown in Fig. 4.

The temperature distribution in the Argon between the RV and GV is shown in Fig. 8. Overall there is little azimuthal variation and a small radial variation; the primary variation is in the axial direction. The temperature distribution in the air between the GV and the $\mathrm{CC}$ is shown in Fig. 9. As was the case in steady state, the primary temperature variation is axial in this upward flowing field; there is a minor radial variation and negligible azimuthal variation. The average exit temperature of the air is $125^{\circ} \mathrm{C}\left(257^{\circ} \mathrm{F}\right)$. The power being removed by the RVACS is $2.4 \mathrm{MW}\left(8.3 \times 10^{6}\right.$ $\mathrm{Btu} / \mathrm{hr}$ ), which is in reasonable agreement with (but $2 \%$ less than) the core power generation. The air removes $56 \%$ of the power by convective cooling at 
the outer surface of the GV; the other $44 \%$ of the power leaving the GV is radiated to the inner surface of the $C C$, where it is then transferred to the air by convection. Figure 10 shows a typical radial temperature distribution, from the hot pool through the air, at the top of the model; the temperature change across this region is $509^{\circ} \mathrm{C}\left(916^{\circ} \mathrm{F}\right)$, which is $30 \%$ bigger than at steady state (cf. Fig. 16 of Ref. 2); the majority (67\%) of this radial temperature change in the current calculation occurs between the GV and the air, which is a noticeable increase from the $45 \%$ share attributable to this gap at steady state.

\section{B. With Overflow}

A QSS calculation was also performed for the situation in which sodium from the hot pool was allowed to overflow through the slots in the top of the RVL into the gap between the RVL and the RV. This was accomplished by setting the surface permeability of the RVL to $20 \%$ (rather than zero) at axial level $K=19$; the rest of the input to COMMIX was identical to that used for the case without overflow.

The overall characteristics of the primary sodium velocity distribution are shown in Fig. 11. As was found in the case without overflow, the sodium flow is up through the pump duct, down through the piping to the core inlet plenum, and upward through all assemblies, with a circulation pattern evident in the UIS region. The primary path for return of the sodium in the hot pool to the cold pool is via the RVL/RV gap, rather than through the IHX. The $38 \mathrm{~mm}(1.5 \mathrm{in})$ space between the RVL and the RV presents less resistance to the flow than is presented by 4000 tubes in the IHXs with an inside diameter of $17 \mathrm{~mm}$ ( $0.67 \mathrm{in})$. The total sodium mass flow rate through the core is $43 \mathrm{~kg} / \mathrm{s}\left(0.34 \times 10^{6} \mathrm{lbm} / \mathrm{hr}\right)$; this is $27 \%$ larger than the flow rate calculated under QSS conditions without overflow (reflecting the decreased resistance of the return path) and is $1.9 \%$ of the steady-state value (resulting in a power-to-flow ratio of 0.31 ). The net mass flow through the IHX is actually upward in this case, at a rate of $0.8 \mathrm{~kg} / \mathrm{s}$ (2 $\mathrm{lbm} / \mathrm{s}$ ) which is essentially negligible since it corresponds to only $2 \%$ of the core flow. Below the bottom of the RVL/RV gap, the flow is essentially the same as found in the case without overflow. 
The velocity distribution in the Argon region is shown in Fig. 12. The entire height of this field is in the same double circulation pattern found in the upper portion of this region for the calculation without overflow. The velocities are much smaller than in the previous case and relatively insignificant; $99 \%$ of the heat transfer from the RV to the GV is by thermal radiation.

The overall character of the temperature distribution is shown in Fig. 13. As was found in the case without overflow, the temperature undergoes little change between the pump and the core inlet, entering the assemblies at a temperature of $592^{\circ} \mathrm{C}\left(1097^{\circ} \mathrm{F}\right)$. The temperature peaks at $638^{\circ} \mathrm{C}\left(1180^{\circ} \mathrm{F}\right)$ at the top of the fuel in the driver assemblies. The temperature rise across the core is consistent with the power-to-flow ratio after accounting for radial conduction through the assembly walls and fixed shielding, which is significant as was found in the case without overflow. The temperature is fairly uniform in the UIS region and the upper hot pool. The flow from this pool enters the top of RVL/RV gap at a temperature of $631^{\circ} \mathrm{C}\left(1168^{\circ} \mathrm{F}\right)$ and exits the bottom of the gap at a temperature of $604^{\circ} \mathrm{C}$ $\left(1119^{\circ} \mathrm{F}\right)$ as shown in Fig. 14; the sodium in this gap is losing energy through the RVL to the primary sodium in the pump and IHX regions and through the RV to the Argon. As in the case without overflow, the cold pool is not uniform in temperature; the sodium exiting the bottom of the RVL/RV gap decreased by $20^{\circ} \mathrm{C}\left(36^{\circ} \mathrm{F}\right)$ before reaching the bottom of the fixed shields. About half of this temperature loss is recovered during the flow upward through the fixed shields to the pump inlet plenum. The lowest sodium temperature is $580^{\circ} \mathrm{C}\left(1076^{\circ} \mathrm{F}\right)$ and located at the bottom of the RV. Overall, the sodium temperatures in this case are somewhat hotter than in the case without overflow but this difference $\left(5^{\circ} \mathrm{C}\right.$ or $\left.9^{\circ} \mathrm{F}\right)$ does not seem to be significant.

The temperature distribution in the Argon space between the $\mathrm{RV}$ and the GV is shown in Fig. 15; the distribution is similar to that found for the case without overflow, only somewhat smoother and showing somewhat higher temperatures. The temperature distribution in the air is shown in Fig. 16; the distribution has characteristics similar to that found for the case without overflow. The average exit temperature of the air is $128^{\circ} \mathrm{C}\left(262^{\circ} \mathrm{F}\right)$, which is $3^{\circ} \mathrm{C}\left(5^{\circ} \mathrm{F}\right)$ higher than for the case without overflow. The power 
being removed by the RVACS is $2.5 \mathrm{MW}\left(8.5 \times 10^{6} \mathrm{Btu} / \mathrm{hr}\right)$ which balances the power being generated in the core (actually exceeding it by $1 \%$ ). The heat transfer at the outer surface of the GV has the same split between convective $(56 \%)$ and radiative $(44 \%)$ components as found in the case without overflow. Figure 17 shows a typical radial temperature distribution, from . the hot pool through the air, at the top of the hot pool; the overall radial temperature change between the hot pool and the air is the same as calculated for the case without overflow; however, allowing flow of sodium from the hot pool to the RVL/RV gap leads to slightly higher temperatures $\left(3-21^{\circ} \mathrm{C}\right.$ or $\left.5-38^{\circ} \mathrm{F}\right)$ in this region.

\section{CONCLUSIONS}

The present calculations have shown the three-dimensional fluid flow and temperature fields expected in the PRISM system during an RVACS transient about 1 day after initiation. Sodium circulates through the primary system in a natural convection mode, as driven by thermal gradients. The heat generated in the fuel, which is all from fission product decay, is all ultimately removed from the RV by the passive operation of the RVACS. Although the power-to-flow ratio in the core is low $(0.3$ to 0.4$)$, the temperature of the primary sodium is $150-270^{\circ} \mathrm{C}\left(270-490^{\circ} \mathrm{F}\right)$ hotter than calculated at fuli-power/full-flow conditions; the hotter primary sodium temperatures are directly related to the air temperature and energy removal mechanisms in the RVACS. Even with this temperature increase, the primary sodium is still more than $250^{\circ} \mathrm{C}\left(450^{\circ} \mathrm{C}\right)$ below its boiling point. Although the temperature distribution within the hot pool retains its uniformity, thermal gradients are present in the cold pool.

The calculations with COMMIX indicate that allowing for overflow of hot pool sodium into the gap between the RVL and the RV has little apparent impact on the long-term heat removal capability when calculated on a quasisteady-state basis. The overflow of hot sodium into the RVL/RV gap increases the average RV temperature by $11^{\circ} \mathrm{C}\left(20^{\circ} \mathrm{F}\right)$ which slightly enhances heat removal from the primary system via the RVACS. The most noticeable effect of allowing overflow into the RVL/RV gap is its potential for leading 
to flow stagnation (or reversal) on the primary side of the IHX; again, this had little significance in the present calculation. The effects of the overflow path, however, may be important for other transients in which the intermediate loop is intended to provide some level of ( $f$ low and) heat removal capability and need to be investigated further.

\section{REEERENCES}

1. "PRISM: Reactor System (SDD-31)," Spec. No. 23A3110, General Electric Corp., Rev. A (September 1985).

2. P. L. Garner, "Three-Dimensional Thermal-Hydraulic Analysis of PRISM at Steady State Using COMMIX-1AR," ANL-PRISM-28, Argonne National Laboratory (August 1986).

3. F. F. Chen, P. L. Garner, and D. J. Malloy, "Preliminary Design ComMIX1A Three-Dimensional Analysis," ANL-PRISM-6, Argonne National Laboratory (January 1986).

4. F. F. Chen, H. N. Chi, W. T. Sha, and V. L. Shah, "Development of a Thermal Radiation Model for the COMMIX-1A Computer Code," ANL-85-48, Argonne National Laboratory (September 1985).

5. J. H. Tessier, unpublished data (January 20, 1986). 


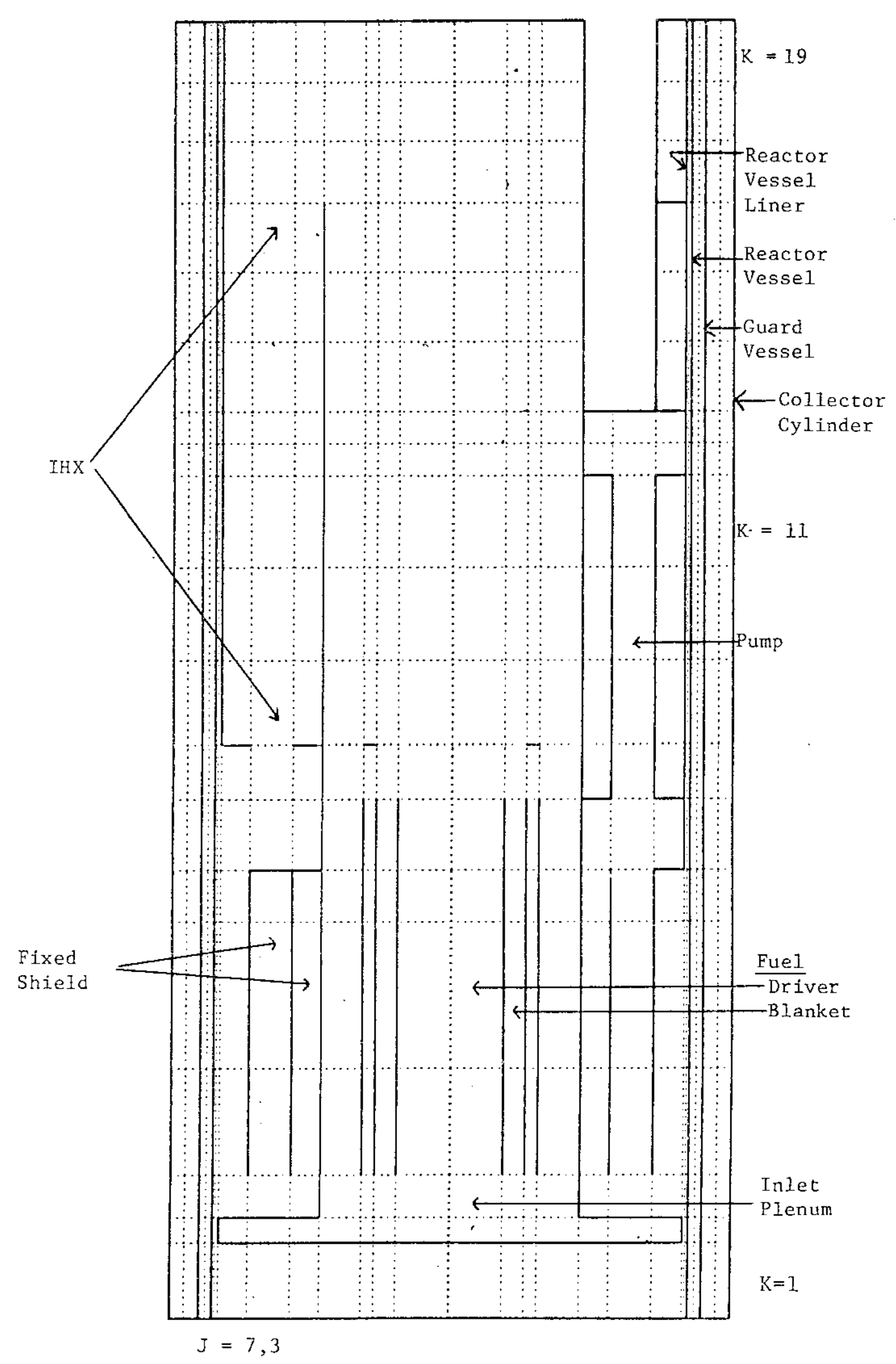

Fig. 1. Elevation View of COMMIX Model at Azimuthal Planes $\mathrm{J}=7$ and 3 


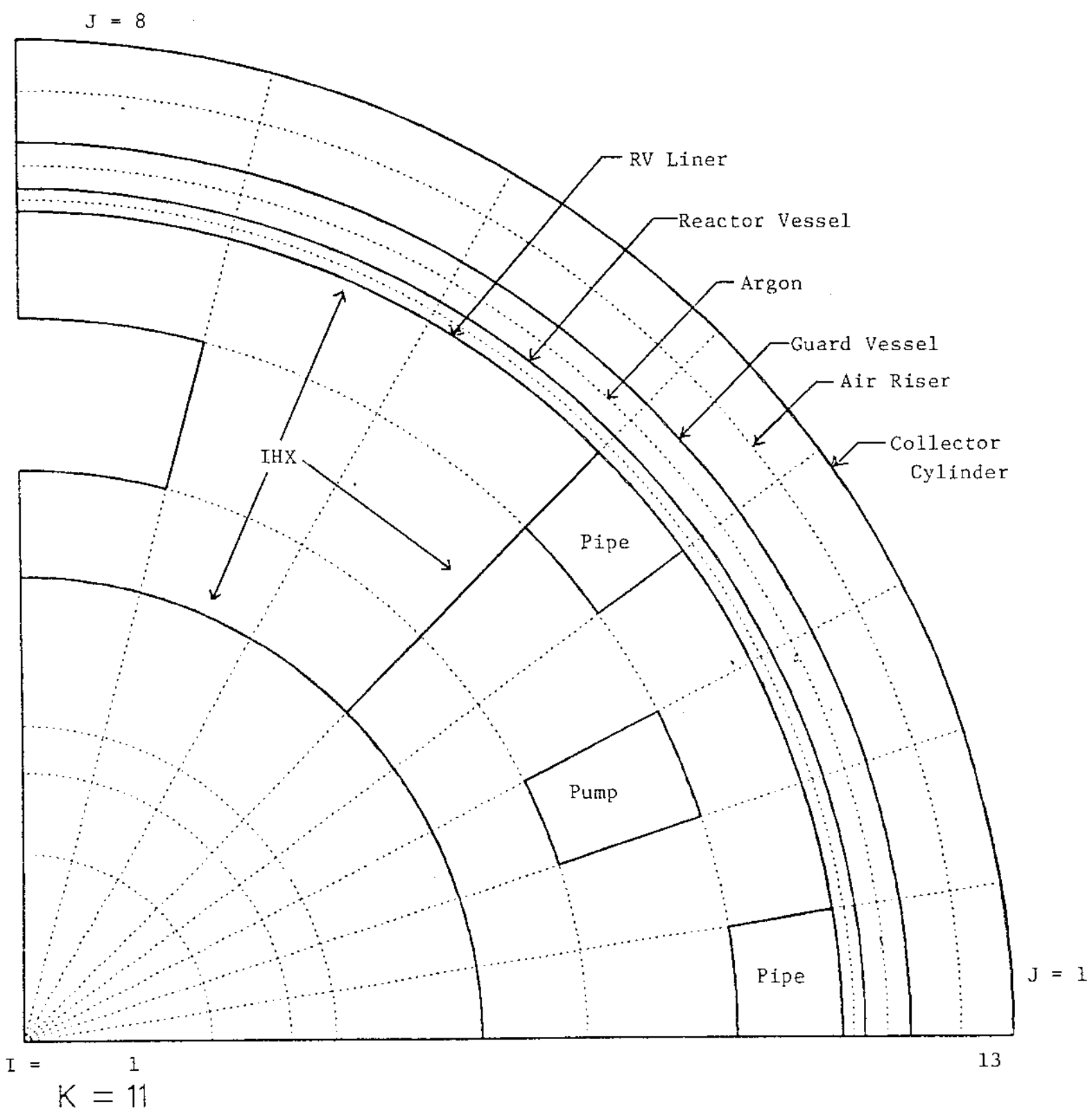

Fig. 2. Plan View of CoMmrX Model Just Below Pump Outlet Plenum (Axial Plane $\mathrm{K}=11$ ) 


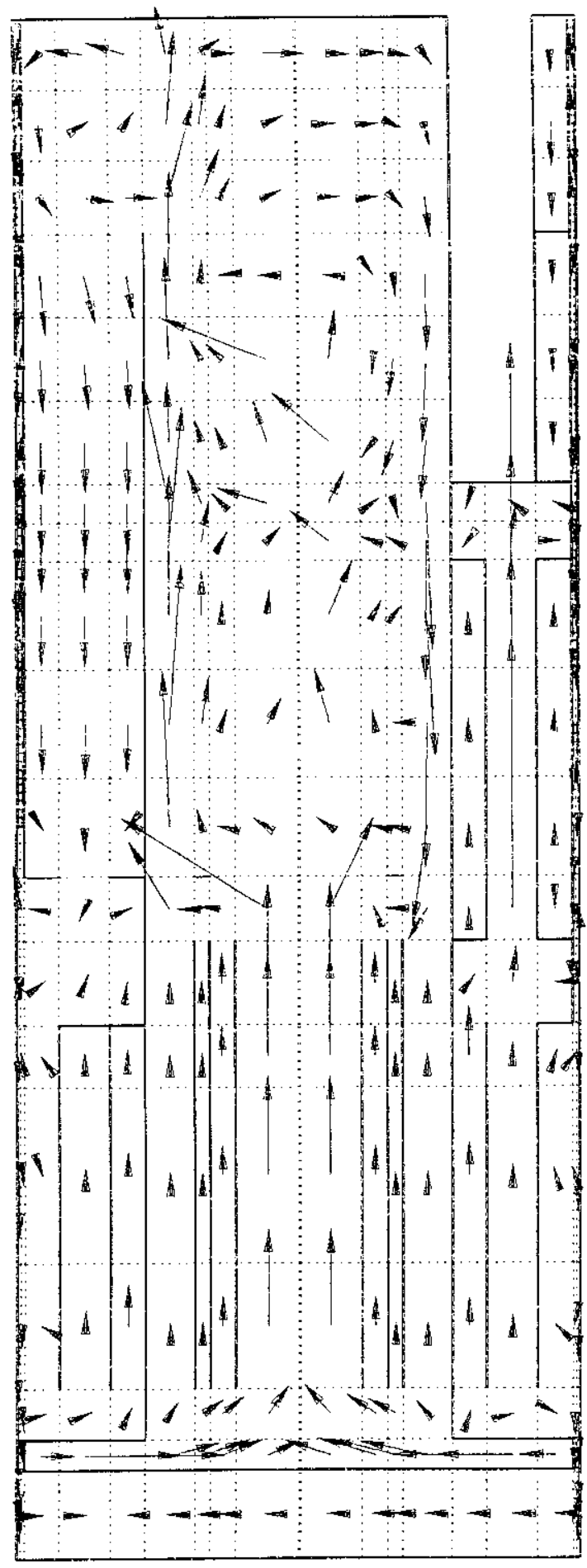

$$
J=7,3-0.15 \mathrm{M} / \mathrm{S}(6 \mathrm{in} / \mathrm{s})
$$

Fig. 3. Elevation View of Velocity Distribution Calculated by COMMIX for QSS at 1 Day Without Overflow 


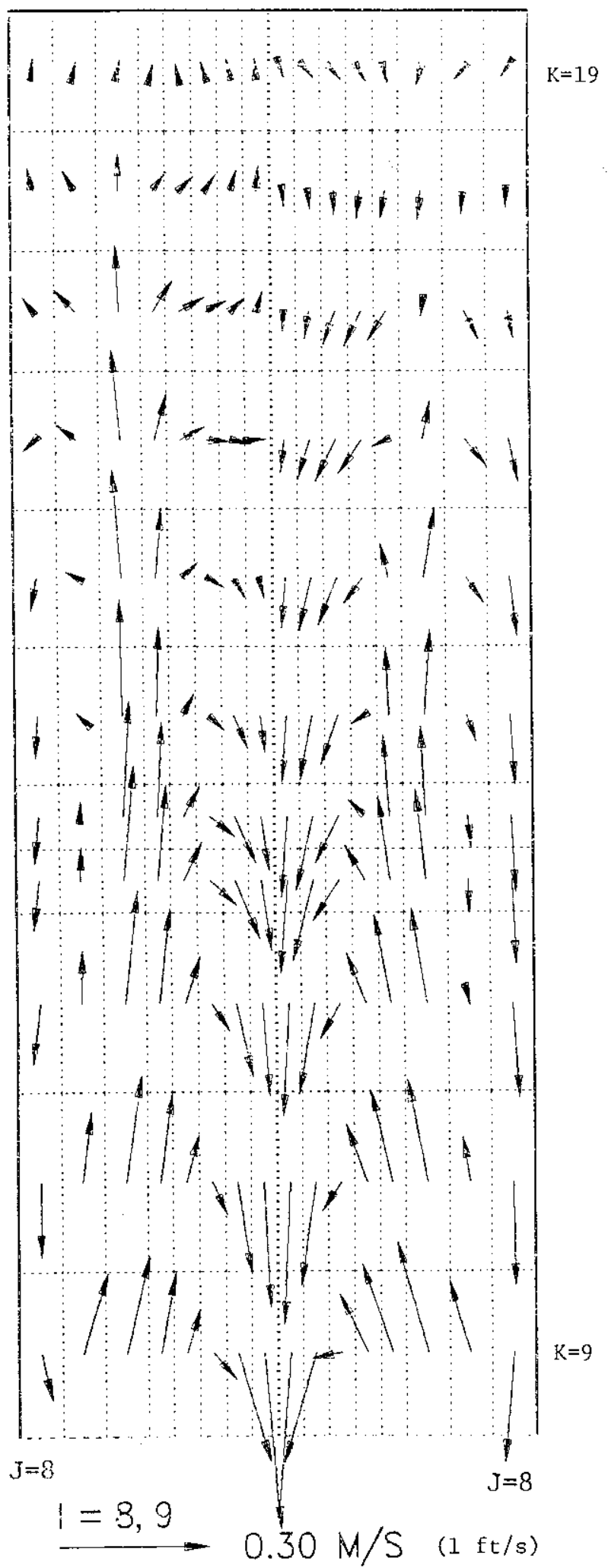

Fig. 4. Velocity Distribution Calculated by COMMIX in RVL/RV Gap for QSS at 1 Day Without Overflow 


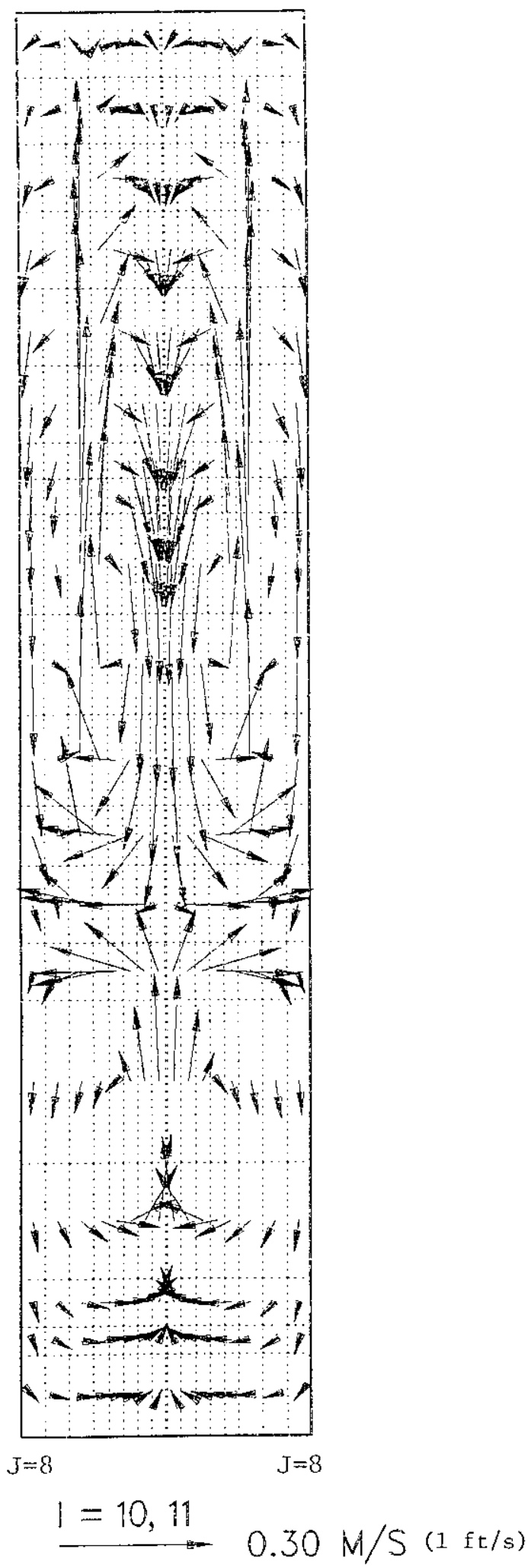

Fig. 5. Velocity Distribution Calculated by ComMIX in RV/GV Gap for QSS at 1. Day Without Overflow 


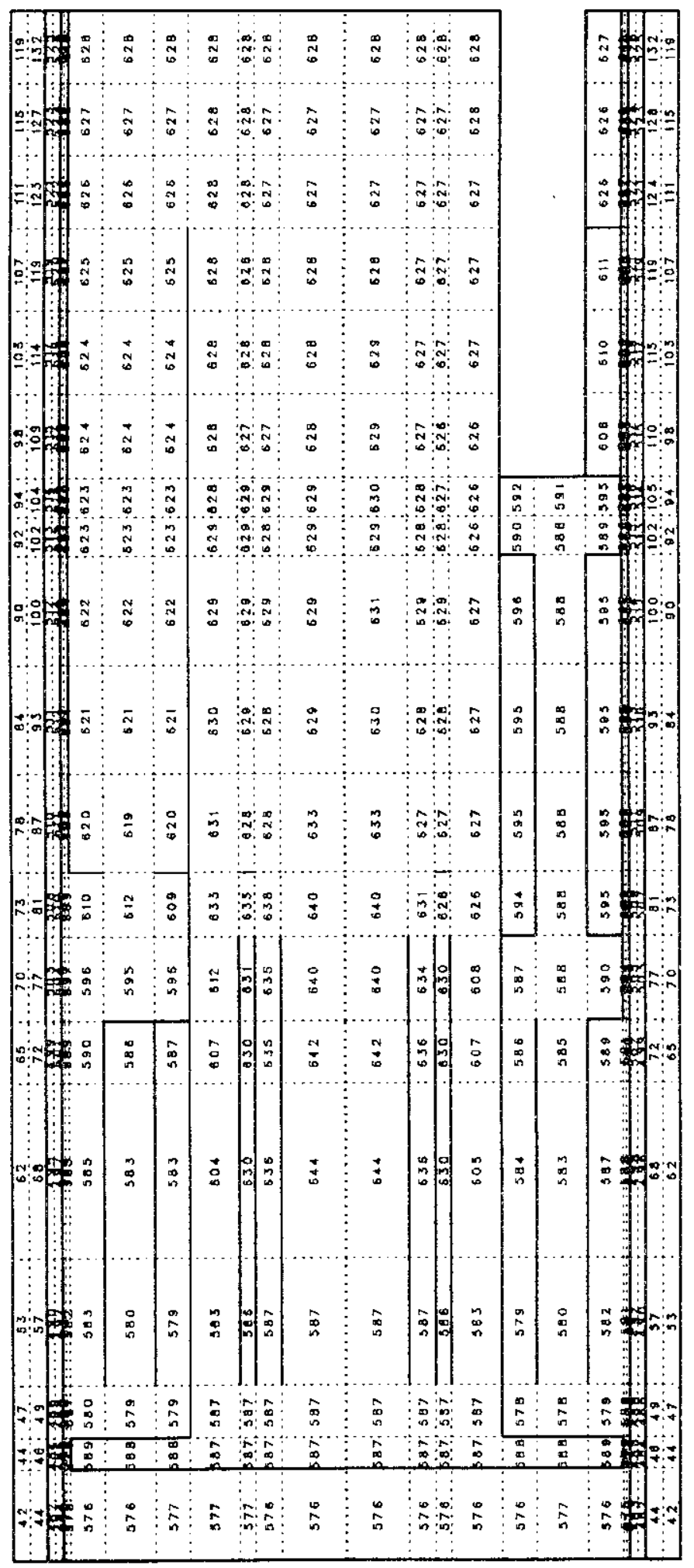

$$
\mathrm{J}=7,3
$$

Fig. 6. Elevation View of Temperature Distribution $\left[{ }^{\circ} \mathrm{C}\right]$ Calculated by COMMIX for QSS at 1 Day Without Overflow 


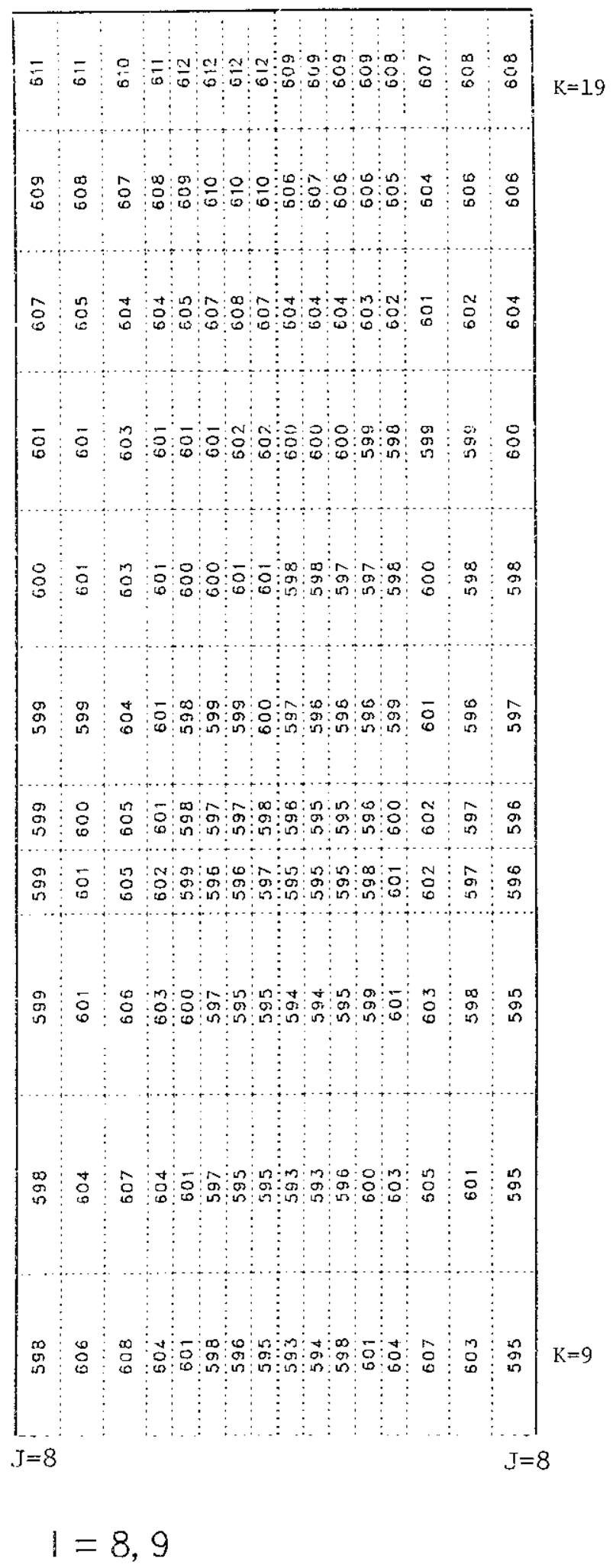

Fig. 7. Temperature Distribution $\left[{ }^{\circ} \mathrm{C}\right]$ Calculated by COMMIX in RVL/RV Gap for QSS at 1 Day Without Overflow 


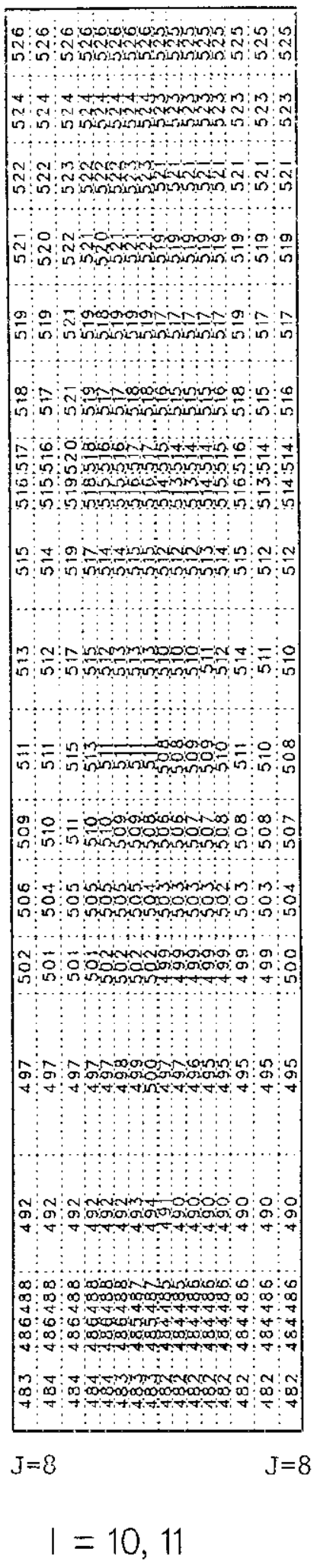

Fig. 8. Temperature Distribution $\left[{ }^{\circ} \mathrm{C}\right]$ Calculated by COMMIX in RV/GV Gap for QSS at 1 Day Without Overflow 


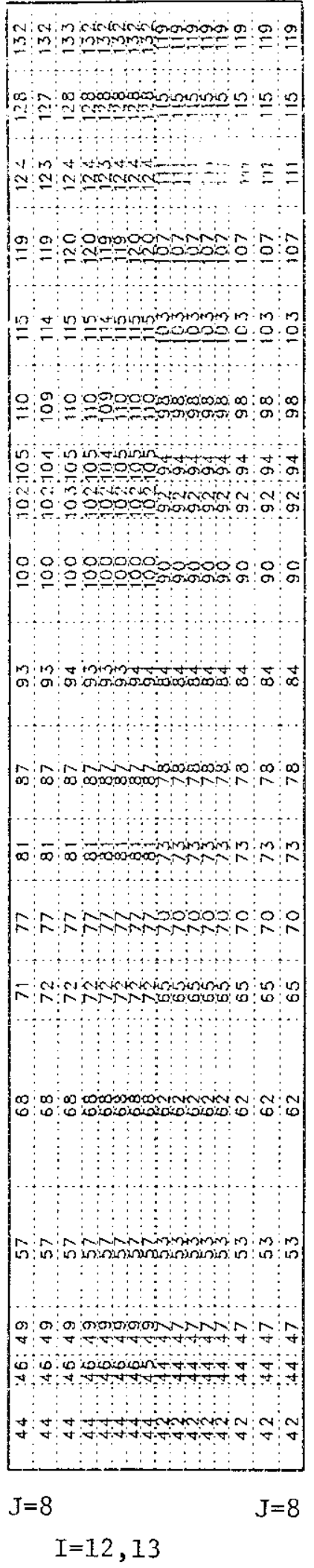

Fig. 9. Temperature Distribution $\left[{ }^{\circ} \mathrm{C}\right]$ Calculated by COMMIX in GV/CC Gap for QSS at 1 Day Without Overflow 


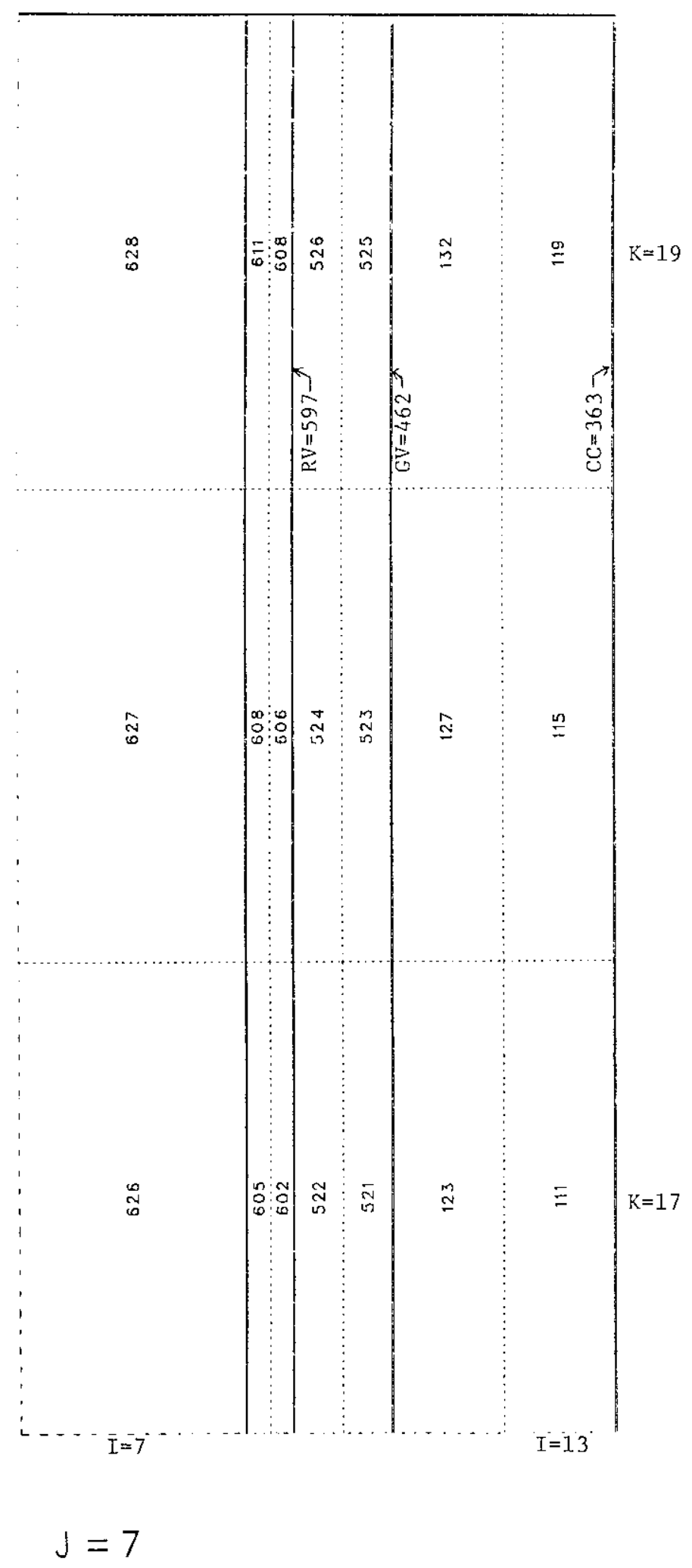

Fig. 10. Representative Radial Temperature Distribution $\left[{ }^{\circ} \mathrm{C}\right]$ Calculated by COMMIX at Top of Hot Pool for QSS at 1 Day Without Overflow 


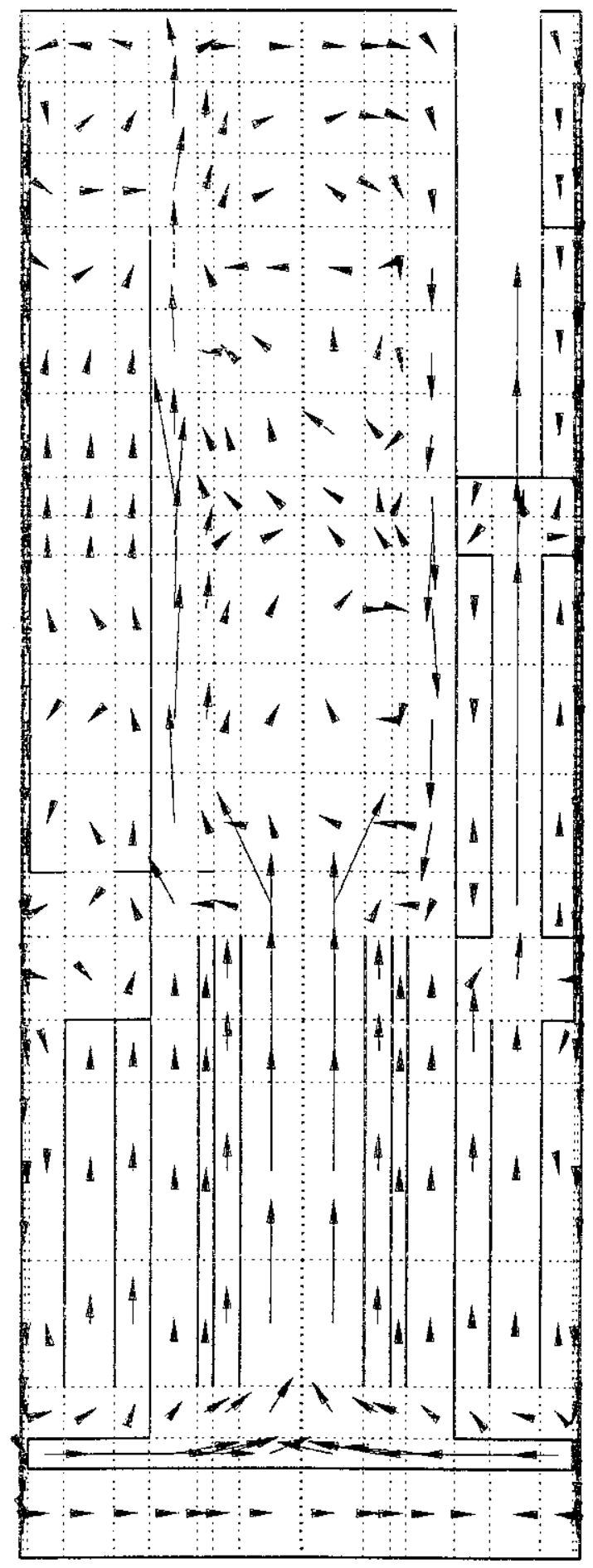

$$
\stackrel{J=7,3}{L} 0.15 \mathrm{M} / \mathrm{S} \quad(6 \mathrm{in} / \mathrm{s})
$$

Fig. 11. Elevation View of Velocity Distribution Calculated by COMMIX for QSS at 1 Day With Overflow 


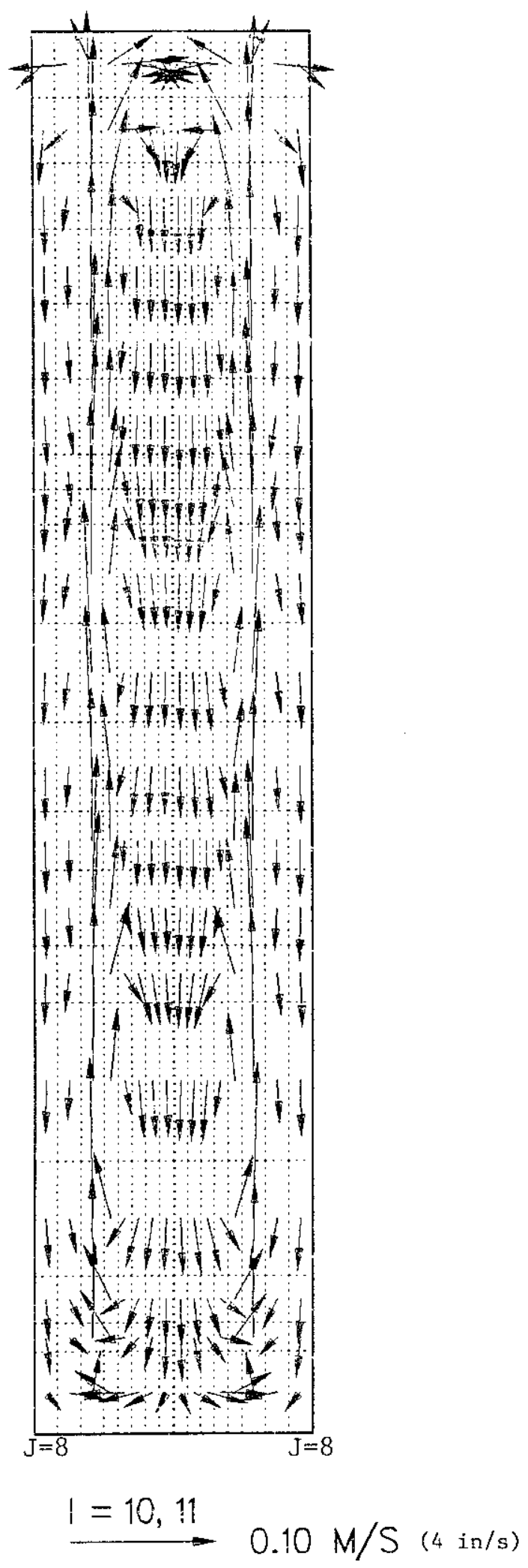

Fig. 12. Velocity Distribution Calculated by COMMIX in RV/GV Gap for QSS at 1 Day With Overflow 


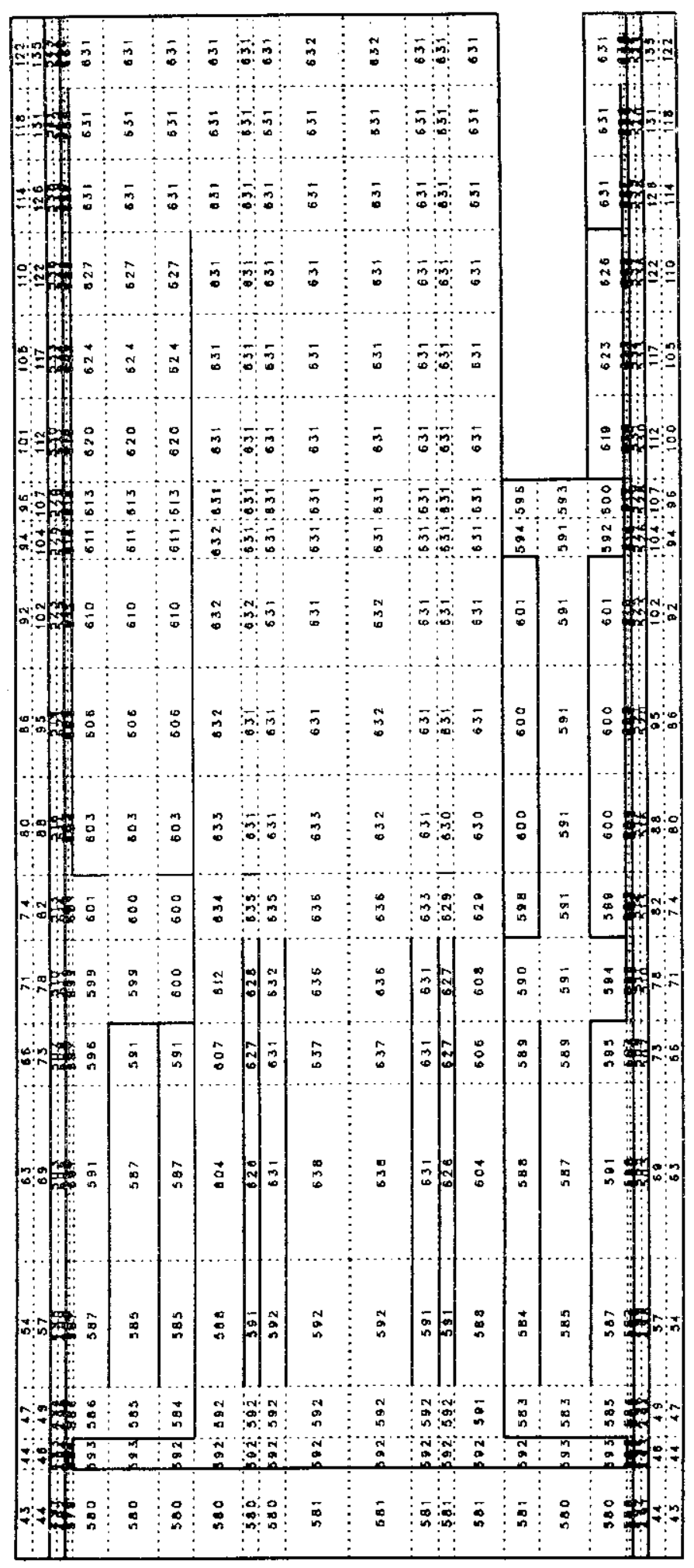

$$
\mathrm{J}=7,3
$$

Fig. 13. Elevation View of Temperature Distribution $\left[{ }^{\circ} \mathrm{C}\right]$ Calculated by COMMIX for QSS at 1 Day with overflow 


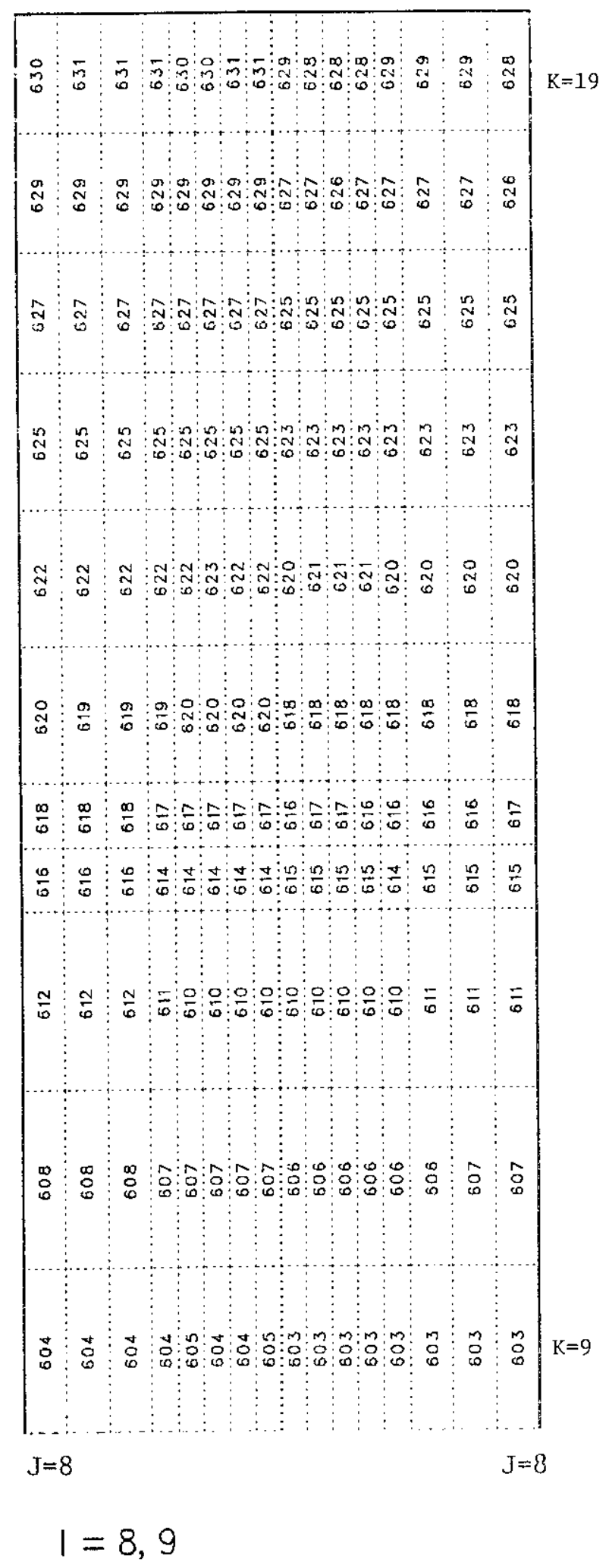

Fig. 14. Temperature Distribution $\left[{ }^{\circ} \mathrm{C}\right]$ Calculated by COMMIX in RVL/RV Gap for QSS at 1 Day With overflow 


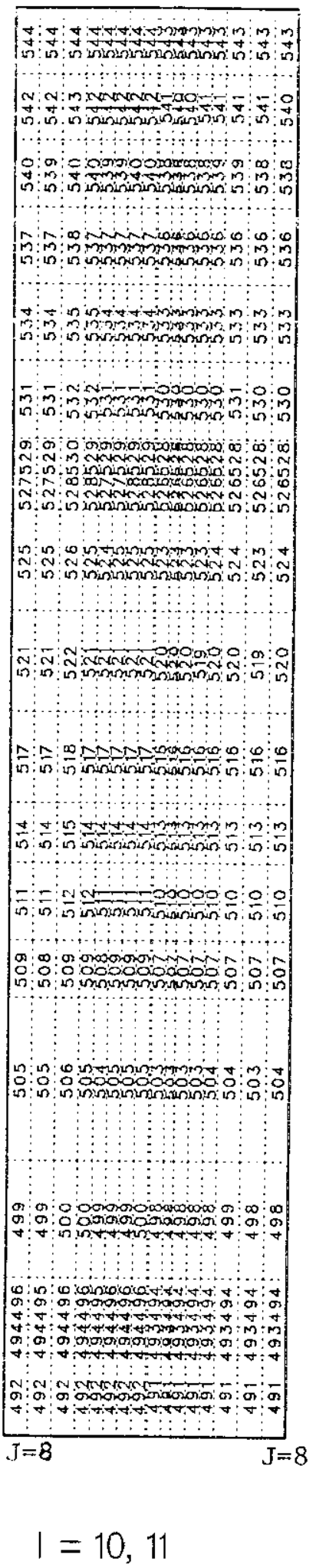

Fig. 15. Temperature Distribution $\left[{ }^{\circ} \mathrm{C}\right]$ Calculated by COMMIX in RV/GV Gap for QSS at 1 Day With Overflow 


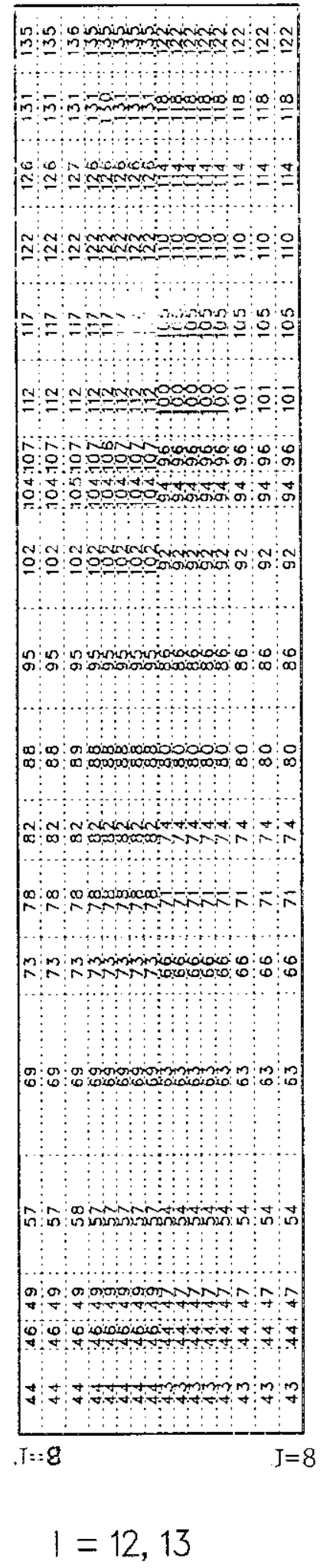

Fig. 16. Temperature Distribution $\left[{ }^{\circ} \mathrm{C}\right]$ Calculated by COMMIX in GV/CC Gap for QSS at 1 Day With Overflow 


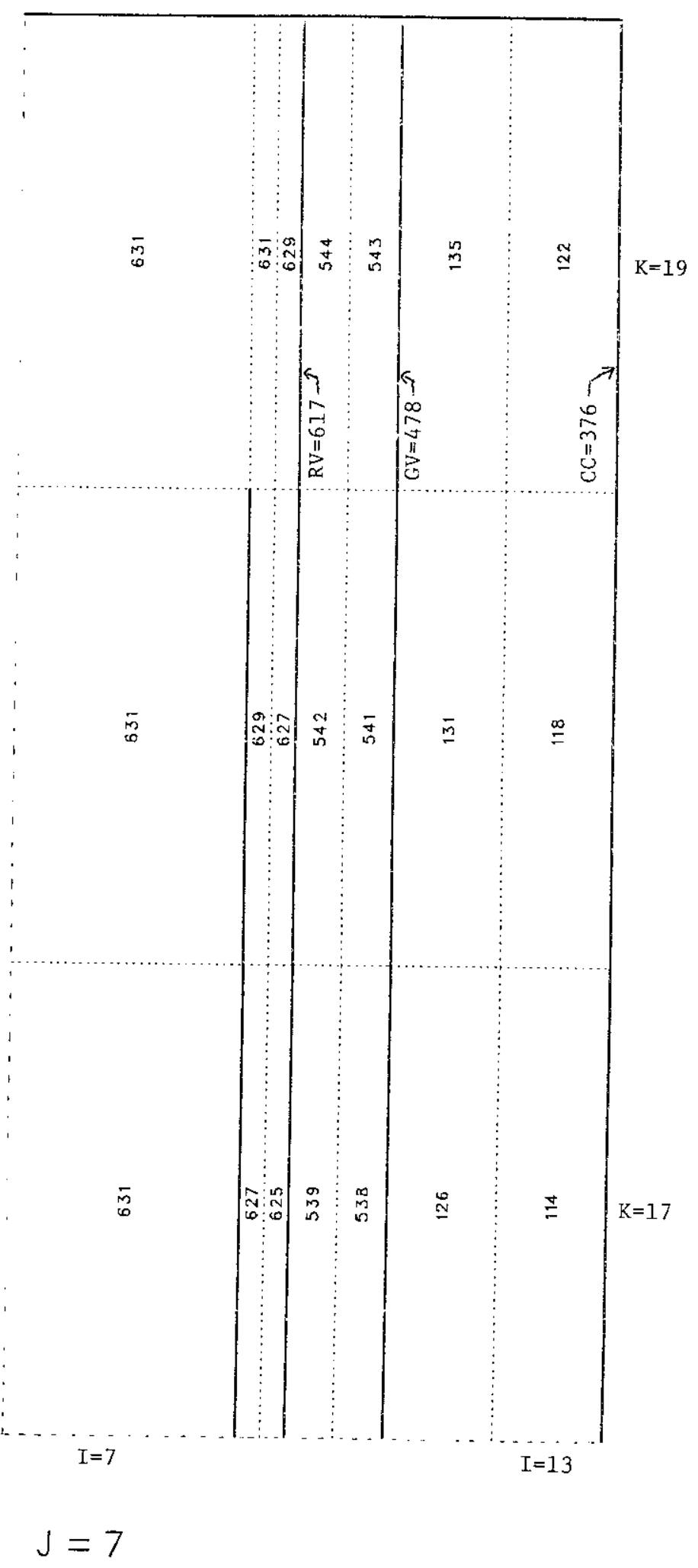

Fig. 17. Representative Radiai Temperature Distribution [ $\left.{ }^{\circ} \mathrm{C}\right]$ Calculated by COMMIX at Top of Hot Pool for QSS at 1 Day With Overflow 


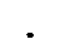




\section{$A-1$}

APPENDIX A: Figures Showing Temperatures in Alternate Units

In the main body of the text, figures showing temperatures were prepared using units of degrees Celsius. As an aid to comparing these results with others, an alternate set of figures using units of degrees Fahrenheit has been prepared and included as this appendix. The figure numbering follows that of the main text; for example, Fig. A-6 of this appendix is the presentation in $\left[{ }^{\circ} \mathrm{F}\right]$ of the information previously shown in $\left[{ }^{\circ} \mathrm{C}\right]$ as $\mathrm{Fig} .6$ in the main text. 


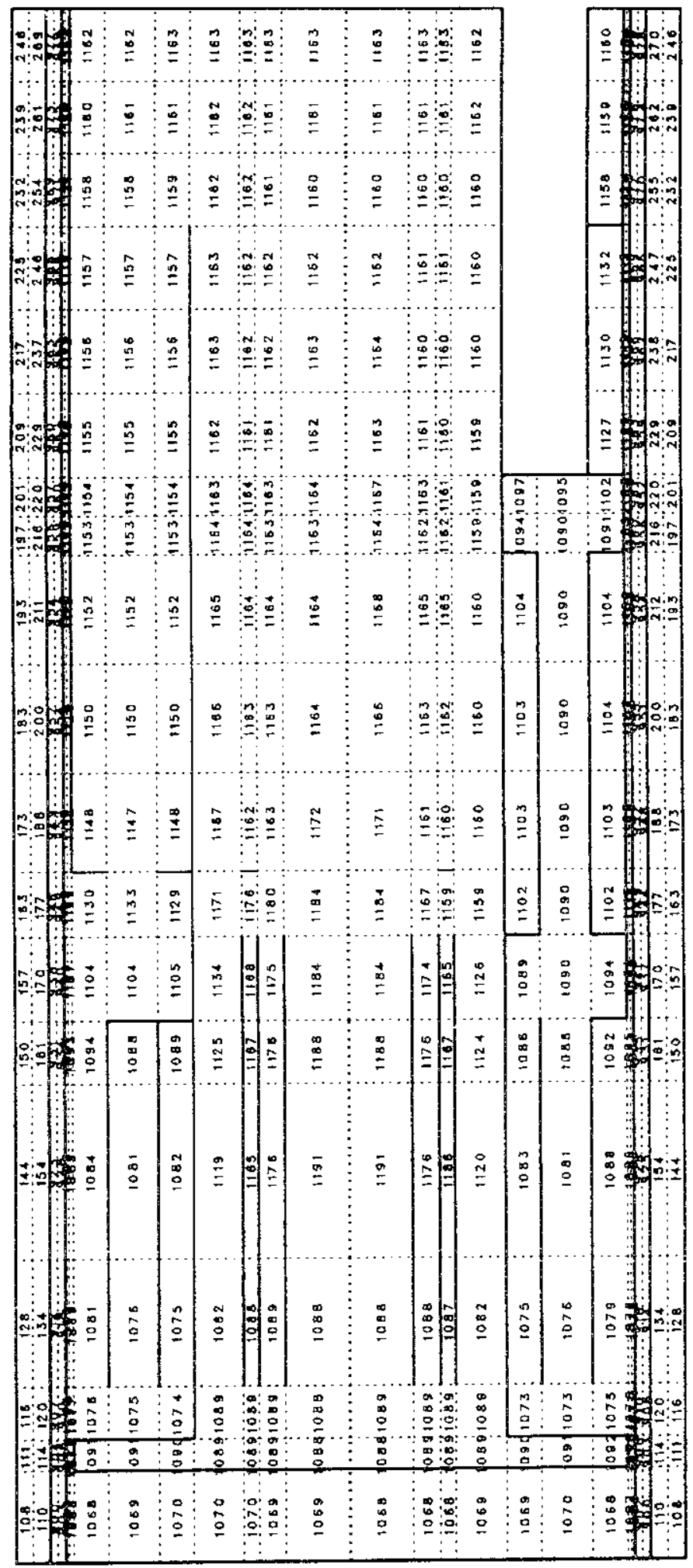

$$
J=7,3
$$

Fig. A-6. Elevation View of Temperature Distribution [ ${ }^{\circ} \mathrm{F}$ ] Calculated by COMMIX for QSS at 1 Day Without Overflow 


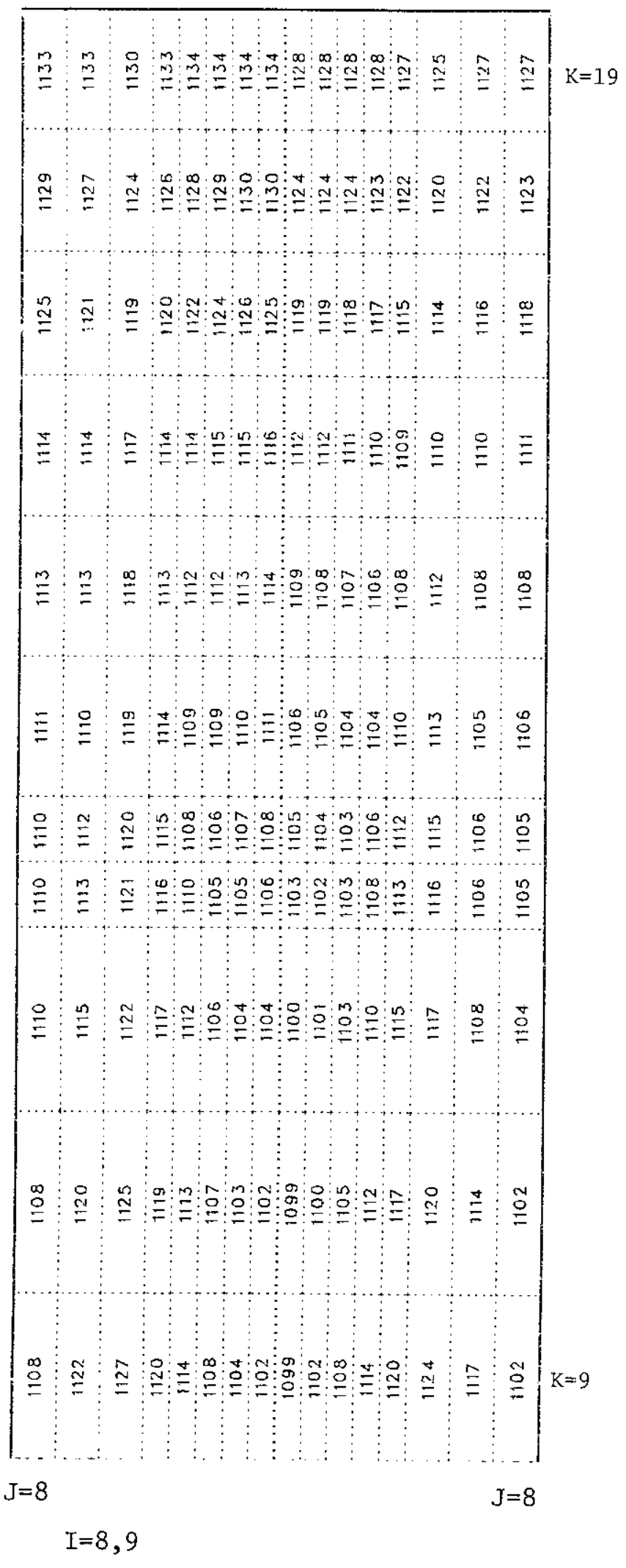

Fig. A-7. Temperature Distribution $\left[{ }^{\circ} \mathrm{F}\right]$ Calculated by COMMIX in RVL/RV Gap for QSS at 1 Day Without Overflow 


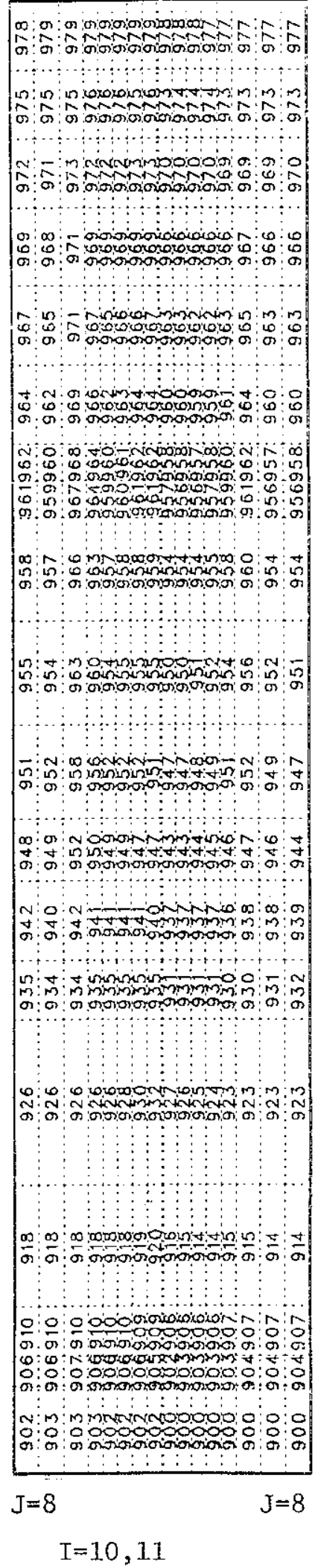

Fig. A-8. Temperature Distribution [OF] Calculated by COMMIX in RV/GV Gap for QSS at 1 Day Without Overflow 


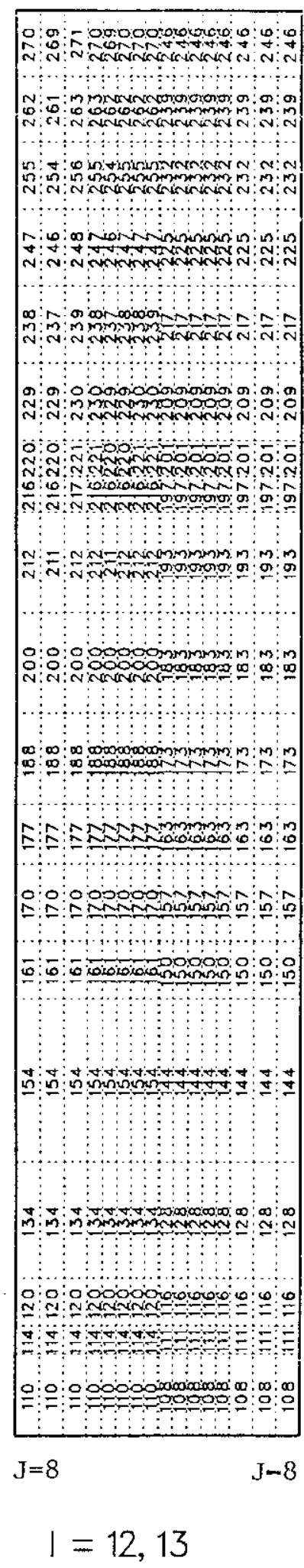

Fig. A-9. Temperature Distribution $\left[{ }^{\circ} \mathrm{F}\right]$ Calculated by COMMIX in GV/CC Gap for QSS at I Day Without Overflow 


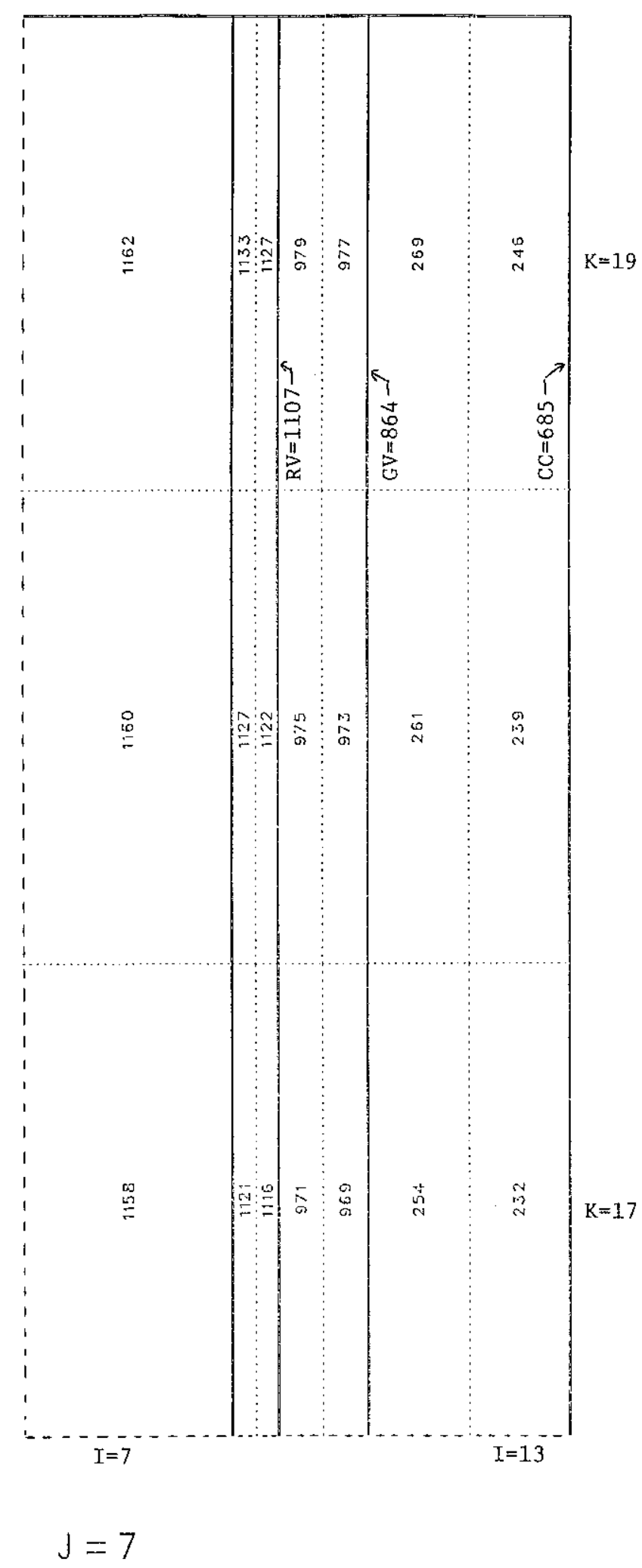

Fig. A-10. Representative Radial. Temperature Distribution $\left[{ }^{\circ} \mathrm{F}\right]$ Calculated by COMMIX at Top of Hot Pool for QSS at 1 Day Without Overflow 


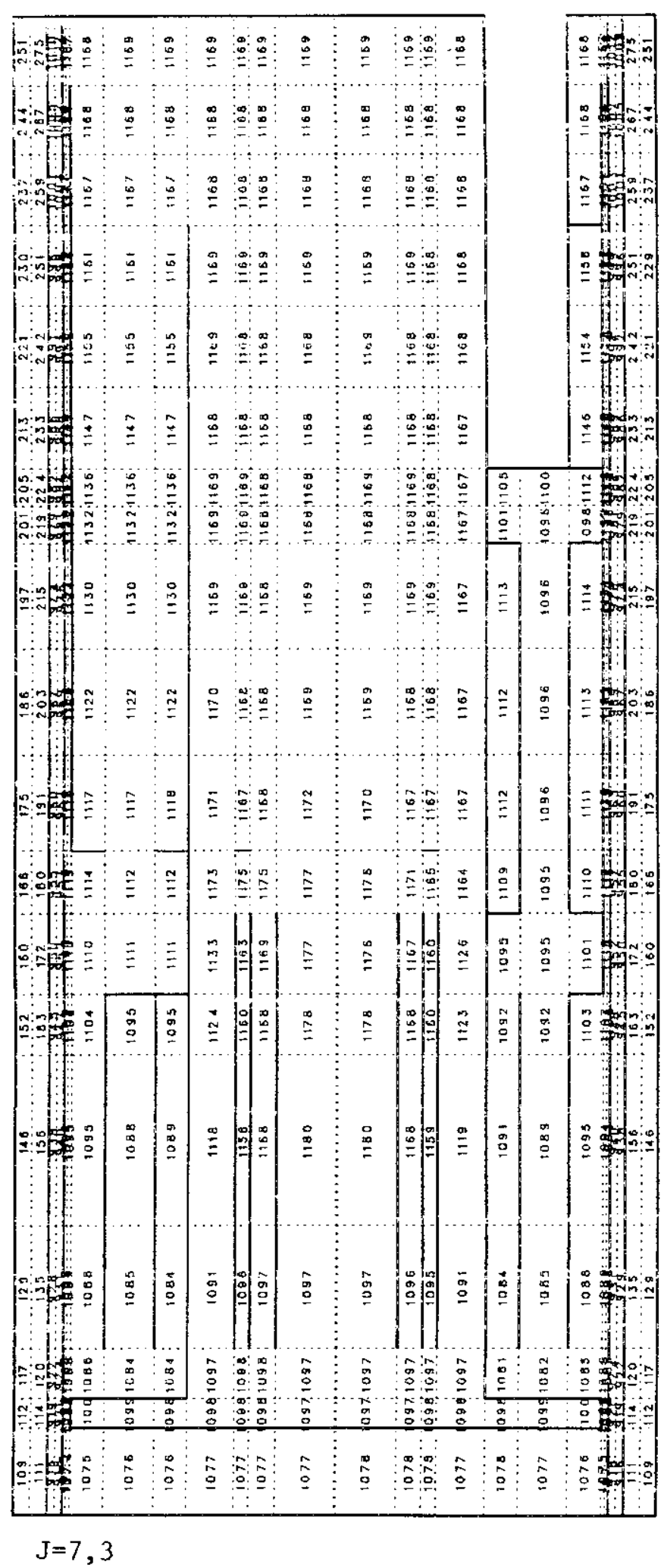

Fig. A-13. Elevation View of Temperature Distribution [ $\left.{ }^{\circ} \mathrm{F}\right]$ Calculated by COMMIX for QSS at 1 Day With Overflow 


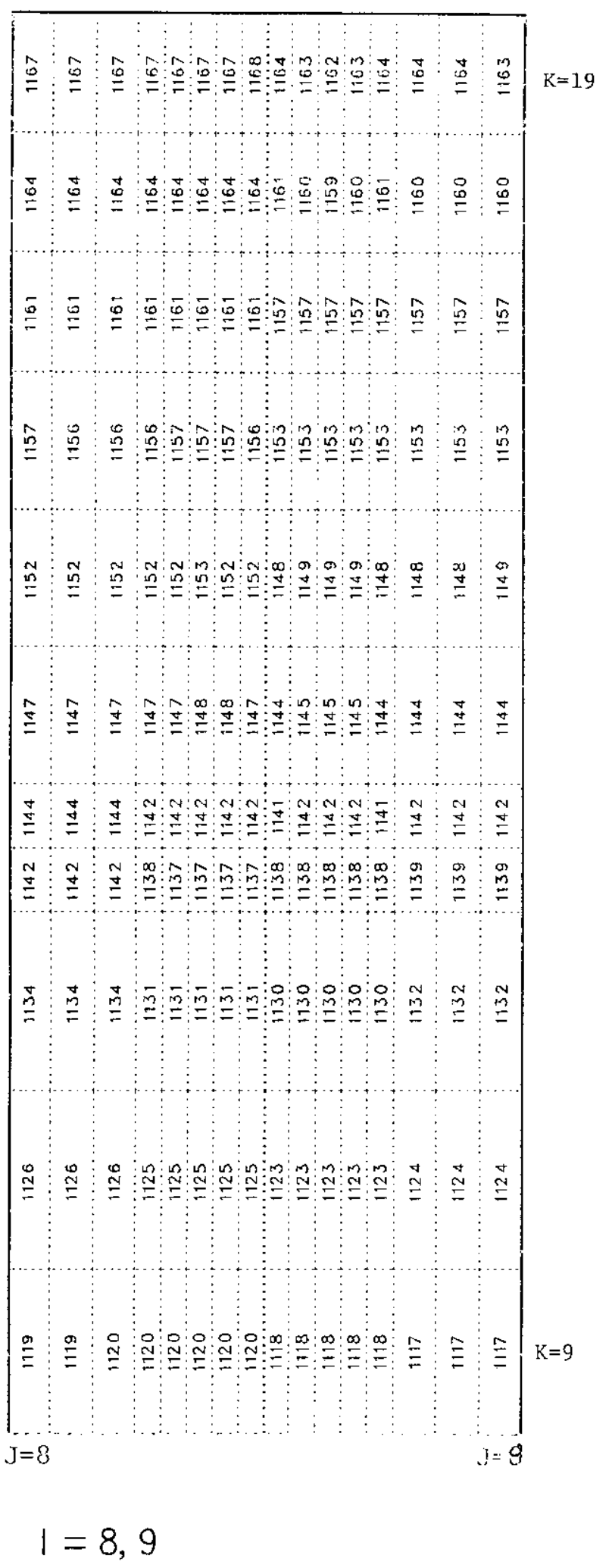

Fig. A-14. Temperature Distribution [ $\left.{ }^{\circ} \mathrm{F}\right]$ Calculated by COMMIX in RVL/RV Gap for QSS at 1 Day With Overflow 


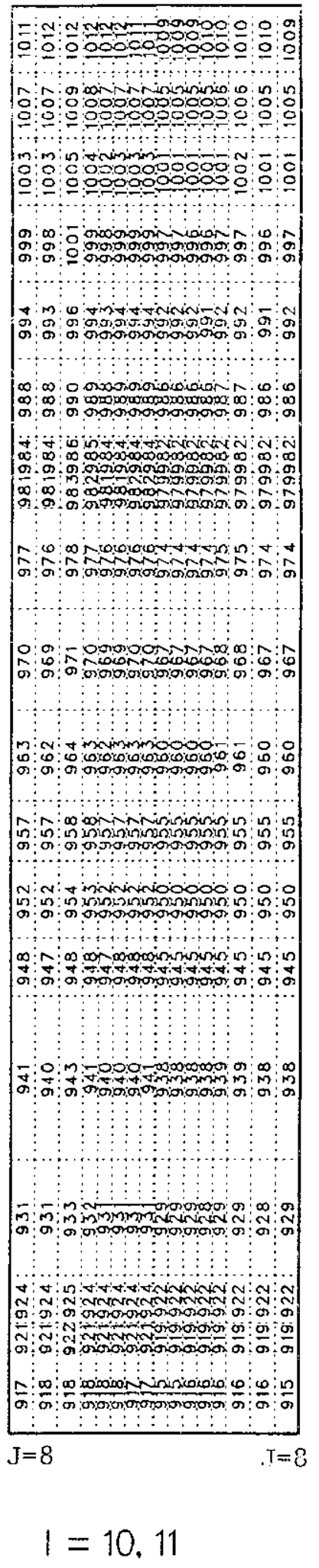

Fig. A-15. Temperature Distribution $\left[{ }^{\circ} \mathrm{F}\right]$ Calculated by COMMIX in RV/GV Gap for QSS at 1 Day With Overflow 


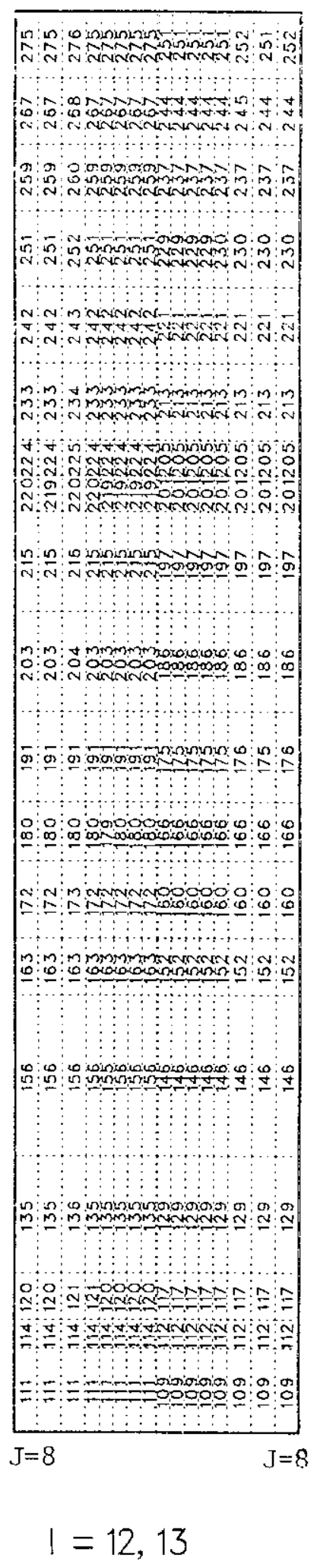

Fig. A-16. Temperature Distribution [ $\left.{ }^{\circ} \mathrm{F}\right]$ Calculated by COMMIX in GV/CC Gap for QSS at 1 Day With Overflow 
A-11

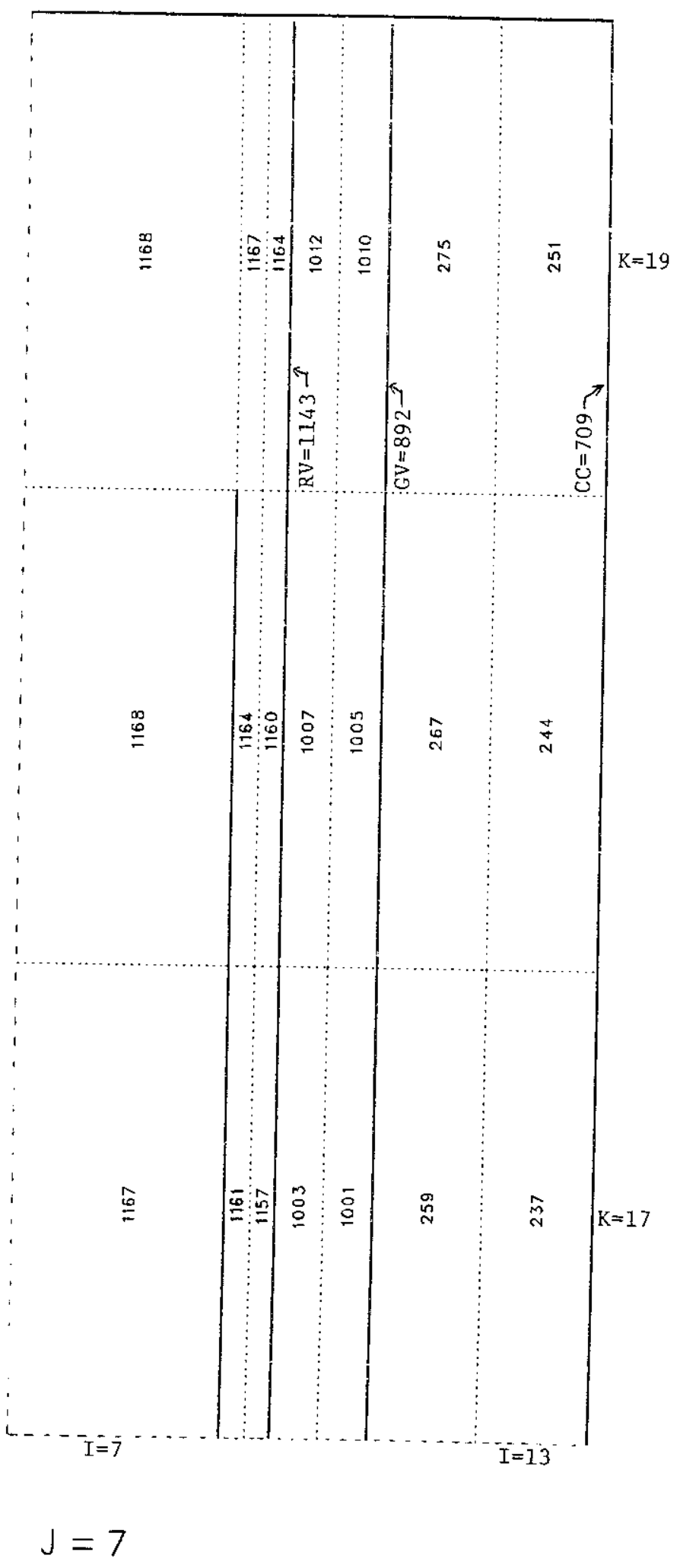

Fig. A-17. Representative Radial Temperature Distribution [ ${ }^{\circ} \mathrm{F}$ ] Calculated by COMMIX at Top of Hot Pool for QSS at 1 Day with Overflow 
